\title{
Um estudo da qualidade da informação censitária em listas nominativas e uma aproximação da estrutura ocupacional da província de Minas Gerais
}

\author{
Marcelo Magalhães Godoy* \\ Clotilde Andrade Paiva**
}

\begin{abstract}
Este artigo objetiva evidenciar a necessidade da avaliação da qualidade da informação censitária em listas nominativas de habitantes do século XIX, propor classificação, segundo a qualidade da informação, para as unidades espaciais de informação do Censo de 1831-32, realizado na província de Minas Gerais, e apresentar resultados preliminares e gerais da estrutura ocupacional de Minas, com base no referido Censo, que contemplam a diversidade regional da província. A demonstração do efeito da qualidade da informação de ocupação sobre a estrutura ocupacional, em três níveis de agregação (provincial, regional e distrital), evidenciou que o trabalho com censos históricos não pode prescindir da avaliação do alcance e limites dos dados.
\end{abstract}

Palavras-chave: Qualidade da informação censitária. Estrutura ocupacional. Minas Gerais. Século XIX.

\section{Introdução}

Para o período pré-censitário, os estudos de estruturas ocupacionais de populações de espaços regionais do Brasil basearam-se, em larga medida, em dados originários de listas nominativas de habitantes. ${ }^{1}$ Entretanto, parece que pouco se realizou no sentido de avaliar a qualidade dos dados procedentes dessa modalidade de fonte demográfica, mormente da informação de ocupação. ${ }^{2}$

Também é possível afirmar que o exame do comportamento demográfico da população brasileira do século XIX quase sempre se pautou, ainda que implicitamente, pela consideração do caráter próprio a sociedades fortemente vincadas pelo relativo

\footnotetext{
* Doutor em História Econômica - USP, professor do Departamento de Ciências Econômicas - Face/UFMG, pesquisador do Cedeplar/Face/UFMG.

** Doutora em História Social - USP, professora do Departamento de Demografia - Cedeplar/Face/UFMG, pesquisadora do Cedeplar/Face/UFMG.

${ }^{1}$ Conquanto localizados e estudados dados populacionais, com a informação de ocupação, na forma de arrolamentos nominais regionais ou locais, para diversas capitanias e províncias, as bases de dados demográficos dessa natureza mais importantes, sobretudo para o século XIX, referem-se a Minas Gerais, Paraná e São Paulo. Quanto à produção historiográfica a contemplar estruturas ocupacionais, ressalta a grande concentração de investigações para os espaços mineiro e paulista.

2 Fernandéz (1989) e Nozoe e Costa (1991) são dois exemplos conspícuos da ainda exígua produção orientada para a avaliação da qualidade dos dados demográficos para o período pré-censitário. Os dois estudos referem-se a arrolamentos nominais de população para São Paulo, entre o final do século XVIII e início do seguinte.
} 
isolamento geográfico, assim como pelo pronunciado condicionamento das específicas configurações de suas economias regionais. Todavia, parece que muito se precisa avançar na direção da compreensão da diversidade interna às grandes unidades político-administrativas ou, em outra forma, de elementos que imponham tratamento regionalizado dos espaços provinciais. ${ }^{3}$

Enfatiza-se, ainda, a relevância de procedimentos metodológicos que intentem enfrentar as dificuldades inerentes a essa modalidade de informação demográfica ou, em outros termos, ao imprescindível estudo dos limites e possibilidades de dados demográficos produzidos segundo critérios nunca inteiramente recuperáveis. Como para qualquer tipo de fonte histórica, a utilização de listas nominais de habitantes deve ser precedida de crítica que contemple a consistência interna e externa do documento e estabeleça, como mencionado, suas possibilidades e limites.

São objetivos deste estudo: evidenciar a necessidade da avaliação da qualidade da informação censitária em listas nominativas de habitantes do século XIX; propor classificação, segundo a qualidade da informação, para as unidades espaciais de informação do Censo de 1831-32, realizado na província de Minas Gerais; e apresentar resultados preliminares e gerais da estrutura ocupacional de Minas, com base no referido Censo, que contemplam a diversidade regional da província.

\section{Uma proposta de avaliação da qualidade da informação de ocupação}

O Censo de 1831-32 é, certamente, o mais extenso e circunstanciado levantamento populacional realizado em Minas Gerais, no período pré-censitário. As listas nominativas remanescentes apresentam satisfatória cobertura e representatividade, abrangendo aproximadamente $60 \%$ dos distritos de paz e da população de Minas, em meados da quarta década do século XIX. Foram relacionados, para cada indivíduo recenseado, o prenome, a condição social, a cor/origem e a idade. Sobrenome, estado conjugal, ocupação, nacionalidade e relações de parentesco ou subordinação socioeconômica foram informados para parcela da população.

No transcurso das últimas três décadas, o Censo de 1831-32 constituiu a base de dados demográficos mais utilizada por pesquisadores da história de Minas Gerais, no período provincial. Independente da temática e do recorte espacial, o Censo de 1831-32 foi inestimável a todos que tencionaram incorporar dados sobre a população mineira na primeira metade do Oitocentos. Salientam-se também as múltiplas possibilidades de articulação dessas informações censitárias com dados originários de outras modalidades de fontes, notadamente de fundos paroquiais e cartoriais. ${ }^{4}$

Entretanto, é evidente o descompasso entre a utilização generalizada das informa-

\footnotetext{
${ }^{3}$ A tardia integração do mercado interno brasileiro em bases capitalistas, processo que se inicia na segunda metade do século XIX e que se acelera após 1930, implicou o isolamento das economias regionais e a impossibilidade, sob risco de anacronismo histórico, de qualquer abordagem agregada (CANO, 1985). No caso de algumas economias regionais, também é imprescindível considerar a ausência de integração interna e a vigência de grande diversidade intrarregional, como é o caso emblemático de Minas Gerais (PAIVA; GODOY, 2002).

${ }^{4}$ Ainda está por se realizar inventário da extensa produção historiográfica que utilizou dados do Censo de 1831-32. Desde o início da década de 1980, o recurso aos dados do Censo de 1831-32 se tornou habitual para pesquisadores dos mais diversos espaços regionais e locais de Minas Gerais, bem como das mais variadas temáticas. Temas como escravidão, família, crescimento e distribuição da população no espaço, composição étnica, estrutura ocupacional, desenvolvimento de específicas atividades econômicas, entre tantos outros, foram investigados com base nos dados do Censo de 1831-32. Tornou-se recorrente a articulação das listas nominativas com múltiplas fontes, como inventários, registros paroquiais, fontes fiscais, arrolamentos nominais de outra natureza (como listas eleitorais e militares), com mapas de população, entre outras.
} 
ções do Censo e a preocupação em avaliar a qualidade dos dados. Pouco se realizou na direção do robustecimento de crítica que contemplasse as consistências interna e externa dessa documentação, bem como avaliasse suas possibilidades e limites. ${ }^{5}$ Por decorrência, não devem ser poucos os problemas que se acumularam derivados da incompreensão do significado desses dados censitários, da ausência de estudos sistemáticos que objetivassem salientar os riscos inerentes à utilização do Censo de 1831-32 sem a imprescindível crítica documental.

Entre as variáveis do Censo de 183132, a informação de ocupação representa o maior desafio, pela complexidade das categorias apresentadas, diversidade dos padrões informativos e, principalmente, inexistência de parâmetros ou técnicas convencionais que permitam a verificação da consistência dos dados. Não se pode esperar que a informação de ocupação seja submetida aos habituais procedimentos de correção ou padronização utilizados por demógrafos e economistas. Assim, essa variável impõe a elaboração de metodologia específica para avaliar a qualidade da informação e, sobretudo, a conformação de recurso para reduzir ou suprimir os efeitos da omissão ou distorção informativas.

Dois problemas sobressaem quando se considera a variável ocupação do Censo de 1831-32: predomínio da não-informação; e forte tendência à simplificação da informação. Para a maior parte da população arrolada, não foi informada a ocupação. Em parte significativa das listas nominativas, a informação de ocupação esteve limitada a poucas e genéricas categorias. Dois fatores adicionais dificultam o entendimento da vigência desses problemas. Em primeiro lugar, o grande número de listas nominativas em que à omissão informativa está superposta uma simplificação muito provavelmente distorceu a estrutura ocupacional. O segundo fator compreende a impossibili- dade de determinar um padrão informativo, a partir de critérios coevos, que permita a classificação das listas nominativas segundo a qualidade da informação de ocupação.

A omissão informativa é problema com incidência tendencialmente variável no Censo de 1831-32. Além das crianças (entendidas como a população nas duas primeiras faixas etárias, 0-4 e 5-9 anos), a não-informação de ocupação é muito mais incidente para escravos, em geral, e para mulheres livres, em particular. A cor ou raça também determinou a ocorrência da não-informação, conquanto de forma menos regular, resultando em omissão maior para indivíduos de cor em relação aos brancos. É provável que outras variáveis também tenham interferido no recolhimento e registro da informação de ocupação, mesmo que de forma ainda menos regular, como o estado conjugal, com tendência a privilegiar indivíduos casados. Verificou-se, ainda, a recorrência de padrão informativo que destacou o chefe do fogo e relegou os demais indivíduos, ou os não-chefes. A tendência foi informar a ocupação do chefe e omitir a dos demais integrantes do fogo. Esse procedimento de arrolamento, provavelmente, assentava-se no pressuposto de que a profissão ou setor de atividade do chefe determinava a ocupação dos não-chefes, que eram entendidos como subordinados ou dependentes.

A mencionada informação de ocupação simplificada ou genérica produziu efeitos de distorção que atingiram preferencialmente certas categorias ocupacionais do Censo de 1831-32. Em uma estrutura ocupacional simplificada, ganharam relevo categorias abrangentes e, muitas vezes, indeterminadas. Realidade marcada por pronunciada heterogeneidade ocupacional, característica de economia diversificada (MARTINS, 1982; PAIVA, 1996), foi apresentada reduzida a poucas categorias. Da mesma forma, não foram poucos os casos de distritos em que a estrutura ocupacional ficou quase resumida

\footnotetext{
5 Os poucos estudos realizados objetivaram compreender as categorias demográficas e econômicas do Censo de 183132, bem como aferir a qualidade das informações censitárias (PAIVA, 1996).
} 
a duas categorias ocupacionais, uma para homens e outra para mulheres.

Com a metodologia que será apresentada e discutida na sequência, objetiva-se a formulação de proposta de classificação das listas nominativas do Censo de 183132 , segundo a qualidade da informação de ocupação. Pretende-se a hierarquização das listas segundo o grau de vulnerabilidade aos referidos problemas de omissão e distorção informativa. Aspira-se a quadro que possibilite a identificação de universo de listas nominativas com reduzida não-informação de ocupação e pequena incidência de padrão informativo inclinado à simplificação ou generalização. A esse objetivo imediato segue o desígnio de constituir banco de dados que permitirá aproximação, que se acredita sólida, do conhecimento da estrutura ocupacional da província de Minas Gerais.

Resta ainda assinalar que a classificação das listas nominativas, segundo a qualidade da informação de ocupação, muito provavelmente implica determinar hierarquia válida para as outras variáveis do Censo de 1831-32. Significa afirmar que a variável ocupação, pela referida complexidade que Ihe é própria, pode se constituir em aferidora da qualidade geral de todas as informações. Sugere-se, portanto, que a proposta de classificação, que será apresentada e discutida a seguir, deve representar medida geral, ou para todas as variáveis, da qualidade da informação censitária das listas nominativas do Censo de 1831-32.

Foram definidos 16 índices para mensurar a qualidade da informação de ocupação das listas nominativas do Censo de 1831-32. Atribuiu-se peso diferenciado a cada índice, segundo importância presumida na determinação da qualidade da informação de ocupação. Quando se afirma a importância presumida dos índices considerados, reporta-se às salientadas tendências por parte dos responsáveis pelo arrolamento em privilegiar determinadas parcelas da população no que se refere à informação de ocupação. Visto que estas tendências são estatisticamente demonstráveis, considera-se que a incidência da informação de ocupação para determinados grupos da população é indicador da qualidade da informação.
Os 16 índices se dividem entre os que se referem à incidência (ou quantidade) da informação de ocupação para determinadas parcelas da população e aqueles que buscam mensurar a amplitude (ou qualidade) da variação da informação de ocupação por categorias e grupos ocupacionais. A divisão dos índices em três grupos com pesos distintos foi presidida pela consideração da vigência de escala hierárquica de fatores que determinaram o grau de zelo dos responsáveis pelo arrolamento da população. Significa dizer que, quando do máximo de zelo, a informação de ocupação é de boa qualidade segundo todos os índices propostos. No sentido inverso, tende a apresentar desempenho crescentemente negativo, ou menor zelo progressivo no arrolamento da informação de ocupação, uma vez que se desconsiderou o arrolamento da informação de ocupação para certas parcelas da população e/ou se reduziu a qualidade da informação por meio de procedimentos simplificadores ou generalizantes. Segue a relação dos índices e respectivos pesos.

\footnotetext{
Peso I - pontuação 0/4/8

1. Percentual da população total com informação de ocupação.

2. Percentual de não-chefes de fogo com informação de ocupação.

3. Percentual de adultos com informação de ocupação.

4. Percentual de homens escravos com informação de ocupação.

5. Percentual de mulheres escravas com informação de ocupação.
}

Foram definidos como índices de peso I as mensurações da qualidade da informação de ocupação entendidas como principais. Nestes casos, as listas nominativas com padrão informativo de melhor qualidade receberam a máxima pontuação (8), as intermediárias ou na média receberam metade da pontuação (4) e aquelas com padrão informativo de pior qualidade ficaram sem pontuação (0). Foram incluídas, como índices de peso I, as mensurações que cobrem segmentos populacionais com elevada omissão de informação de ocupação (não-chefes de fogo e escravos dos dois sexos), a medida geral da cobertura da informação de ocupação (população 
total) e a mensuração específica que exclui as crianças (população adulta).

A ausência ou baixa incidência de informação para os não-chefes de fogo, ou o exclusivo ou quase exclusivo arrolamento da ocupação para os chefes, padrão vigente em significativa parcela das listas nominativas de 1831-32, resulta em estrutura ocupacional que, como mencionado, não espelha a diversidade ocupacional de Minas Gerais no século XIX. O não arrolamento ou baixa incidência da informação de ocupação para escravos dos dois sexos impede a diferenciação das atividades tipicamente escravistas, impossibilita o conhecimento de divisão social do trabalho em todos os seus matizes setoriais, regionais, étnicos, entre outros. A cobertura geral da informação de ocupação é indicador primeiro para se mensurar o alcance quantitativo da variável ocupacional. A exclusão da população infantil e a mensuração da informação de ocupação para a população adulta significam filtrar categoria que tende não apenas a não ter informada a ocupação, mas também, em grande medida, a estar excluída do mercado de trabalho.

\footnotetext{
Peso II - pontuação 0/2/4

6. Percentual da população com informação de ocupação, excluídas as idades sem informação.

7. Percentual de chefes com informação de ocupação.

8. Percentual de idosos com informação de ocupação.

9. Percentual de mulheres livres com informação de ocupação.

10. Número de ocupações com frequência

11. Número de grupos ocupacionais com frequência.
}

Os índices de peso II incluem as medidas da qualidade da informação de ocupação entendidas como intermediárias ou menos importantes do que as de peso I. Para estes casos, as listas nominativas com padrão informativo de melhor qualidade receberam a máxima pontuação (4), as intermediárias ou na média receberam metade da pontuação (2) e aquelas com padrão informativo de pior qualidade ficaram sem pontuação (0). Foram definidas como índices de peso II três ordens de medidas: a proporção de informação de ocupação em três segmentos de população, sendo dois em que a omissão tende a ser baixa (chefes de fogo e idosos) e um com elevada não-informação (mulheres livres); a mensuração da informação de ocupação a partir da idade em que foi arrolada a ocupação para pelo menos um indivíduo; e o número de ocupações e de grupos ocupacionais com frequência.

Os índices agrupados como peso II foram considerados aferidores da incidência e qualidade da informação de ocupação em posição relativa de segunda importância por incidirem sobre parcela da população que tendeu a ter a informação de ocupação relacionada em todas as listas nominativas (chefes de fogo) e, inversamente, apresentou baixa ou ausente informação no conjunto das listas (idosos). São de segunda importância porque contemplam parcela da população (mulheres livres) para a qual, excluído número menor de listas nominativas, os responsáveis pelo arrolamento inclinaram-se pela omissão ou simplificação, como pode ser constatado pela comparação da estrutura ocupacional da população segundo o sexo, em que a amplitude de categorias de ocupação para as mulheres livres é muito menor do que para os homens livres.

O índice 6 (percentual da população com informação de ocupação, excluídas as idades sem informação) foi incluído no grupo de peso II pelo seu caráter complementar ao índice 3 (percentual de adultos com informação de ocupação), por refinar medida geral com a consideração de particularidades locais e/ou dos responsáveis pelo arrolamento no que tange à determinação de faixa de população entendida como em idade aquém da necessária para a inserção no mercado de trabalho. Também decidiu-se pela inclusão dos índices 10 e 11 (que medem o número de ocupações e grupos ocupacionais com frequência), entre as medidas intermediárias, por se referirem a medidas qualitativas, portanto subordinadas às de peso I. Significa dizer que são medidas relevantes, visto que permitem ultrapassar a simples mensuração da incidência da informação de ocupação, contemplando também a qualidade por meio da amplitude informativa, ainda que não possam ser consideradas mais impor- 
tantes do que a avaliação da presença da informação ocupacional, da qual dependem para serem mensurados.

\footnotetext{
Peso III - pontuação 0/1/2

12. Idade a partir da qual informa a ocupação.

13. Percentual de crianças com informação de ocupação.

14. Percentual de homens livres com informação de ocupação.

15. Percentual das outras ocupações, excluídas as quatro com maior frequência.

16. Percentual dos outros grupos ocupacionais, excluídos os quatro com maior frequência.
}

No peso III foram incluídos os índices que aferem a qualidade da informação de ocupação considerados de menor importância em relação aos pesos I e ll. Nestes casos, as listas nominativas com padrão informativo de melhor qualidade receberam a máxima pontuação (2), as intermediárias ou na média receberam metade da pontuação (1) e aquelas com padrão informativo de pior qualidade ficaram sem pontuação (0). No peso III estão medidas entendidas como complementares e que se dividem em duas modalidades. $\mathrm{Na}$ primeira, encontram-se as mensurações de segmentos populacionais específicos e que tendem a apresentar comportamento pouco variável nas listas nominativas: as crianças, que quase sempre são arroladas sem informação de ocupação; e os homens livres, que invariavelmente constituem a faixa de população com menor omissão. A segunda modalidade inclui medidas complementares a algumas mensurações de peso II: idade a partir da qual a informação de ocupação foi relacionada ao menos para um indivíduo; proporção de outras ocupações excluídas as quatro com maior incidência; e percentual de grupos ocupacionais excluídos os quatro com maior incidência.

Na Tabela 1 são apresentados os parâmetros provinciais, ou que compreendem todas as listas nominativas do Censo de 1831-32, balizadores das mensurações realizadas para cada distrito, ou para cada lista nominativa. Apurou-se o resultado provincial para cada índice, ou o resultado que compreende toda a população (primeira coluna da Tabela 1). A partir desses resultados, foram calculadas as médias que representaram os parâmetros para verificação da qualidade da informação de ocupação em cada lista nominativa do Censo de 1831-32 (segunda coluna da tabela). Realizou-se o cálculo por meio da determinação de variação compreendendo faixa de $10 \%$ acima

TABELA 1

Índices para mensuração da qualidade da informação de ocupação das listas nominativas do Censo de 1831-32 e parâmetros provinciais para avaliação, segundo variáveis selecionadas Minas Gerais

\begin{tabular}{lcc}
\hline Variáveis & Índices & Parâmetros \\
\hline Percentual da população total com informação de ocupação & 39,6 & 35,6 a 43,6 \\
Percentual de não-chefes de fogo com informação de ocupação & 30,4 & 27,4 a 33,4 \\
Percentual de adultos com informação de ocupação & 56,1 & 50,5 a 61,7 \\
Percentual de homens escravos com informação de ocupação & 28,8 & 25,9 a 31,7 \\
Percentual de mulheres escravas com informação de ocupação & 27,9 & 25,1 a 30,7 \\
Percentual da população com informação de ocupação, excluídas idades sem informação & 51,1 & 46,0 a 56,2 \\
Percentual de chefes com informação de ocupação & 89,9 & 80,9 a 98,9 \\
Percentual de idosos com informação de ocupação & 62,2 & 56,0 a 68,4 \\
Percentual de mulheres livres com informação de ocupação & 38,6 & 34,7 a 42,5 \\
Número de ocupações com frequência & 775 & 48 a 58 \\
Número de grupos ocupacionais com frequência & 40 & 24 a 29 \\
Idade a partir da qual informa a ocupação & 10 & 9 a 11 \\
Percentual de crianças com informação de ocupação & 11,5 & 10,4 a 12,7 \\
Percentual de homens livres com informação de ocupação & 51,7 & 46,5 a 56,9 \\
Percentual das outras ocupações, excluídas as quatro com maior frequência & 35,1 & 31,6 a 38,6 \\
Percentual dos outros grupos ocupacionais, excluídos os quatro com maior frequência & 26,7 & 24,3 a 29,4 \\
\hline
\end{tabular}

Fonte: Censo 1831-32. 
a $10 \%$ abaixo do resultado provincial. Por exemplo, para o índice 1, percentual da população total com informação de ocupação, foi realizado o cálculo da variação de $10 \%$ abaixo e $10 \%$ acima de $39,6 \%$, resultando em média provincial entre $35,6 \%$ e $43,6 \%$. $\mathrm{Na}$ determinação da pontuação, para todos os índices, considerou-se a máxima pontuação quando acima da média provincial, pontuação intermediária quando dentro dessa média e sem pontuação quando abaixo da média.

O índice 12, idade a partir da qual informa a ocupação, resultou da determinação da idade a partir da qual a informação de ocupação era regular. Ou, em outros termos, a idade a partir da qual não se identificaram vazios de frequência. Em nível desagregado, ou quando se considerou o resultado para cada lista nominativa, a determinação desse índice alcançou relativa precisão, tendo em vista que o exame da frequência simples das idades permitiu a pronta identificação do ponto em que a informação se tornava regular, e que apresentava incidência significativamente maior do que a encontrada nas idades que lhes eram inferiores. Para a determinação do índice 12 para a província, foi necessário proceder de forma diversa. Neste nível de grande agregado, não existiam vazios de frequência e a apuração baseou-se exclusivamente, a partir do exame da frequência simples das idades, na determinação do ponto a partir do qual a incidência da informação de ocupação tornava-se relativamente alta ou muito maior do que nas idades inferiores. O índice 6 (percentual da população com informação de ocupação, excluídas as idades sem informação) foi calculado com base na população total subtraída dos indivíduos com idade inferior àquela determinada pelo índice 12 .

O índice 10, número de ocupações com frequência, compreende todas as ocupações (categorias ocupacionais) constantes da frequência simples. Ou seja, todas as ocupações que foram arroladas pelo menos uma vez. Da mesma forma, o índice 11, número de grupos ocupacionais com frequência, abarca todos os grupos ocupacionais (corresponde aos subsetores do Quadro 1) representados com pelo menos uma ocupação na frequência simples. Assim, estes índices para a província cobrem todas as ocupações e grupos ocupacionais com frequência no Censo de 1831-32.

Tendo em vista que, para o cálculo da média provincial, não faria sentido considerar os resultados totais (775 ocupações e 40 grupos ocupacionais), pois, naturalmente, nenhum distrito de paz poderia ser submetido a esse parâmetro para aferição da qualidade da informação de ocupação, adotou-se procedimento diferenciado. Presumiu-se que a adoção de dois terços dos grupos significaria ajuste para contemplar a diversidade que se queria aferir. Dessa forma, foi definida a variação entre 24 e 29 grupos (variação de $10 \%$ abaixo e $10 \%$ acima de 26,5 , ou de dois terços dos 40 grupos) como parâmetro para a média provincial. Para a média de ocupações, adotou-se o procedimento de dobrar os números da variação dos grupos, pressupondo a incidência média de duas ocupações por grupo como parâmetro. Assim, foi definida a variação entre 48 e 58 ocupações como média provincial.

Com o índice 15 (percentual das outras ocupações, excluídas as quatro com maior frequência), buscou-se mensurar o peso relativo da preferência por certas categorias. Na determinação do índice para Minas Gerais, procedeu-se à subtração da frequência das seguintes ocupações: lavrador $(30,4 \%)$, fiadeira $(24,5 \%)$, costureira $(5,5 \%)$ e jornaleiro $(4,5 \%)$. Portanto, as demais 771 categorias respondiam por $35,1 \%$ da frequência das ocupações da província. Para a determinação da média, adotou-se a variação percentual válida para os demais índices. No caso do índice 16 (percentual dos outros grupos ocupacionais, excluídos os quatro com maior frequência), realizaramse os mesmos procedimentos do índice 15.

A classificação das listas nominativas do Censo de 1831-32, segundo a qualidade da informação de ocupação, salientou grandes disparidades (ver classificação no Anexo). Considerada a pontuação máxima (74 pontos), constatou-se que pouco mais de um terço das listas nominativas (94 distritos) superou $50 \%$ da pontuação (39 a 74 pontos). A lista nominativa do distrito de Cachoeira do Campo, pertencente ao município de Ouro 
Preto e à região Mineradora Central Oeste, obteve a pontuação máxima em todos os índices. Abaixo de $50 \%$ da pontuação (até 33 pontos), foram classificados quase dois terços das listas nominativas (144 distritos). Sete listas nominativas, correspondentes a distritos de vários municípios e regiões, não pontuaram em todos os índices. Em síntese, não se pode descurar das pronunciadas divergências na qualidade da informação de ocupação do Censo de 1831-32 e, consequência inarredável, é necessário ponderar seu efeito sobre a estrutura ocupacional.

\section{Regionalização para a província de Minas Gerais}

Um dos principais atributos da economia e sociedade provinciais era a diversidade regional (PAIVA; GODOY, 2002). As várias configurações da formação natural e a diferenciada evolução histórica do processo de ocupação do território imprimiram marcantes traços distintivos entre os múltiplos espaços de Minas Gerais (GODOY, 1996). $\mathrm{Na}$ primeira metade do século XIX, as características da organização econômica e os componentes sociodemográficos evidenciavam marcantes contrastes regionais (PAIVA, 1996).

A segmentação do território provincial em unidades regionais é essencial à avaliação da representatividade, assim como a qualquer intenção de análise conjunta dos dados arrolados no Censo de 1831-32. Desconsiderar a diversidade regional como atributo indissociável de Minas Gerais implica submeter-se a sérios riscos de perceber homogeneidade e padrões universais para realidade heterogênea e fortemente vincada por particularismos.

A proposta de regionalização adotada baseou-se, exclusivamente, na percepção do espaço de viajantes estrangeiros que percorreram quase todo o território de Minas Gerais, na primeira metade do século XIX. Do inter-relacionamento de fatores fisiográficos, demográficos, econômicos, administrativos e históricos, logrou-se a divisão de Minas Gerais em 18 regiões (Mapa 1). Embora os aspectos de natureza econômica tenham ocupado posição central, as identidades regionais resultaram de combinações específicas de múltiplos aspectos (GODOY, 1996). 6

\section{Classificação das ocupações do Censo de 1831-32}

Entre sinônimos, variantes vocabulares, ocupações simples e associadas, foram relacionadas milhares de designações no Censo de 1831-32. Sistematizadas e classificadas, as ocupações foram reunidas em quase 800 categorias. Para o estudo da estrutura ocupacional, procedeu-se a setorização desse amplo universo de ocupações. No Quadro 1 estão relacionados os setores e respectivos subsetores.

\footnotetext{
6 Em Intrépidos viajantes e a construção do espaço, uma proposta de regionalização para as Minas Gerais do século XIX (GODOY, 1996), discute-se, sinteticamente, o caráter das viagens dos Oitocentos (os fatores que intervieram na realização das viagens e as motivações que impulsionaram a produção dos relatos, a visão de mundo dos viajantes, o imaginário que compartilhavam e o instrumental de que se utilizaram na apreensão das realidades visitadas), avalia-se a forma dominante de utilização dos relatos de viagem pela historiografia sobre o período provincial mineiro (sugere-se uma nova proposta de trabalho com os depoimentos dos viajantes) e contempla-se uma série de lacunas no estudo destas fontes históricas, apreciam-se a cobertura temporal e a representatividade dos viajantes compulsados e examinam-se a técnica de leitura e a forma de organização das informações retiradas dos relatos de viagem, discutem-se o significado dos conceitos de espaço e região e as distorções usuais na relação dos historiadores com estas categorias. Introduzidos os aspectos mais importantes referentes a fontes, conceitos e metodologia, propõe-se regionalização para as Minas Gerais do século XIX, e são apresentadas as unidades regionais (analisa-se a combinação específica de aspectos de diversas naturezas, principalmente econômicos, que conferiam identidade a cada região). Às regiões, segue-se síntese das principais características da organização econômica da província de Minas Gerais. Os anexos adicionam relação circunstanciada das localidades visitadas pelos viajantes em cada região, mapas com a espacialização dos itinerários em Minas Gerais das 13 viagens contempladas e mapa com a espacialização da regionalização (são apresentadas a proposta original de regionalização e a resultante de alterações posteriores, "regionalização adaptada", que retificou algumas fronteiras, conferindo-lhes maior precisão geográfica e sintonia com divisões administrativas coevas, e redefiniu a distribuição regional de porções do território de Minas Gerais).
} 
MAPA 1

Regionalização e níveis de desenvolvimento econômico das regiões da província de Minas

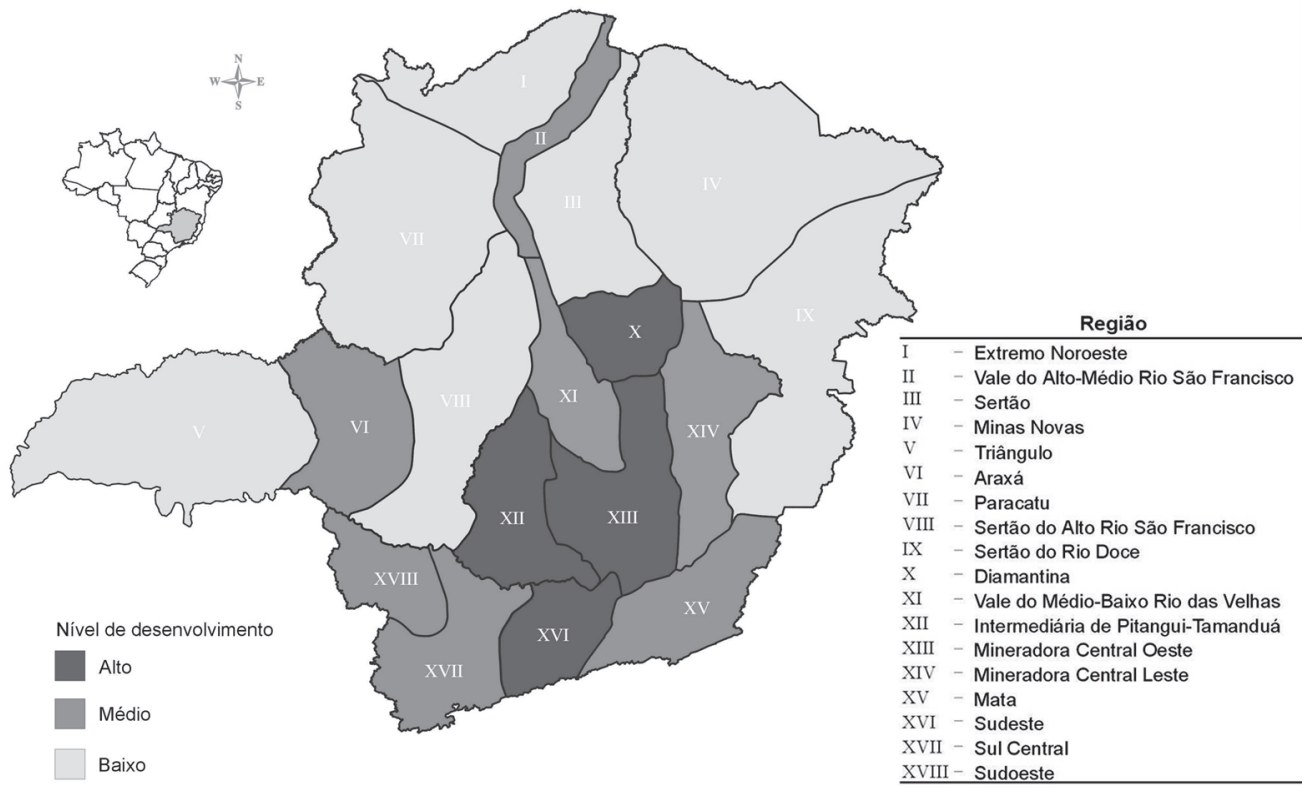

Fonte: IBGE. Malha municipal do Brasil 1997. Diretoria de Geociências. Departamento de Cartografia.

Regionalização: Godoy (1996).

QUADRO 1

Classificação das ocupações do Censo de 1831-32 em setores e subsetores

\begin{tabular}{|c|c|}
\hline \multirow{2}{*}{$\begin{array}{l}100 \text { Agropecuária } \\
101 \text { Agricultura }\end{array}$} & 500 Serviço doméstico \\
\hline & 600 Funções públicas \\
\hline 102 Agroindústria & 601 Civis \\
\hline 103 Pecuária & 602 Militares \\
\hline 104 Atividades agrícolas em geral & 603 Igreja \\
\hline 105 Associações I & 604 Associações I \\
\hline 106 Associações II & \multirow{2}{*}{$\begin{array}{l}700 \text { Outros setores } \\
701 \text { Extrativismo }\end{array}$} \\
\hline 200 Mineração & \\
\hline 201 Mineração & 702 Assalariados \\
\hline 202 Associações I & \multirow{2}{*}{$\begin{array}{l}703 \text { Controle do trabalho escravo } \\
704 \text { Educação }\end{array}$} \\
\hline 300 Atividades manuais e mecânicas & \\
\hline 301 Artífices em madeira & 705 Saúde \\
\hline 302 Artífices em metais & 706 Transportes \\
\hline 303 Artífices em couros e peles & 707 Outras atividades \\
\hline 304 Artífices em barro & 708 Associações I \\
\hline 305 Artífices em fibras & 709 Associações II \\
\hline 306 Artífices em fiação e tecelagem & 800 Desocupados \\
\hline 307 Artífices em tecidos & 801 Deficientes, enfermos e idosos \\
\hline 308 Artífices em edificações & 802 Indigentes \\
\hline 309 Outros artífices & 803 Sem ocupação \\
\hline 310 Associações I & \multirow[t]{6}{*}{900 Associações ocupacionais } \\
\hline 311 Associações II & \\
\hline 400 Comércio & \\
\hline 401 Comércio fixo & \\
\hline 402 Comércio de tropas & \\
\hline 403 Associações I & \\
\hline
\end{tabular}

Fonte: Censo 1831-32. 


\section{Estimativa Populacional para 1831-35}

A Estimativa Populacional para 1831-35 foi originalmente elaborada com vistas a avaliar a representatividade e cobertura espacial das listas nominativas remanescentes do Censo de 1831-32 (PAIVA, 1996, p. 49-53 e 69-74). Iniciativa inédita para a primeira metade do século XIX, a Estimativa permitiu conhecer o tamanho e a distribuição regional da população da província. Excetuado o Censo de 1872-73, que faculta a desagregação da população por paróquias, a Estimativa Populacional para 1831-35 é a única fonte de informação para o período imperial mineiro que possibilita o conhecimento do tamanho de toda a população, segundo pequenas circunscrições administrativas.

Os dados da Estimativa foram recolhidos em quatro bases, com largo predomínio do Censo de 1831-32 e dos Mapas de 1833-35, que juntos responderam por quase $90 \%$ dos distritos e população (Tabela 2). A identificação temporal da Estimativa decorre desse predomínio dos dados referentes ao primeiro quinquênio da década de 1830. A conferência da versão original da Estimativa logrou a incorporação de nove distritos e o acréscimo de 11.709 indivíduos, com a consequente ampliação da qualidade dos dados estimados (GODOY, 2004, p. 679-710).

$\mathrm{Na}$ Estimativa Populacional para 183135 é pronunciada a sub-representação dos indígenas. Foi recenseada apenas pequena parcela dos índios nômades e aldeados, que se distribuíam por várias regiões de Minas Gerais. A baixíssima enumeração é especialmente grave nos casos de Minas Novas, Sertão do Rio Doce e Mata, regiões em que o contingente de indígenas era expressivo e chegava, para parte considerável de seus territórios, a superar a população não-indígena.

A sub-representação também é ponderável para as populações não-indígenas das áreas em processo de colonização como porções dos territórios das regiões do Triângulo, Sertão do Alto São Francisco e Mineradora Central Leste - e dos espaços com reduzida densidade populacional, ausência ou precariedade de rede urbana e economia baseada na pecuária extensiva (especialmente, faixas dos territórios das regiões Extremo Noroeste, Paracatu, Sertão e Minas Novas).

Embora observadas essas restrições que seguramente afetaram, em graus variados, o dimensionamento das populações de determinadas regiões, a Estimativa deve ser considerada a mais apurada e desagregada avaliação geral da população de Minas Gerais, para a primeira metade do século XIX. ${ }^{7}$

\section{Amostra com listas nominativas selecionadas segundo a qualidade da informação de ocupação e a representatividade regional}

Com o objetivo de demonstrar a validade da proposta de classificação das listas

TABELA 2

Estimativas populacionais, segundo fontes de dados Minas Gerais - 1831-35

\begin{tabular}{lcccr}
\hline Fonte de dados & Distritos & População (\%) & Base de dados & Distritos (\%) \\
\hline Cunha Matos - 1826 & 31 & 7,4 & 44.318 & 6,1 \\
Censo de 1831-32 & 234 & 55,8 & 383.946 & 52,5 \\
Mapas de 1833-35 & 140 & 33,4 & 269.045 & 36,8 \\
Censo de 1838-40 & 8 & 1,9 & 22.183 & 3,0 \\
Sem informação (médias) & 6 & 1,4 & 11.286 & 1,5 \\
Total & $\mathbf{4 1 9}$ & $\mathbf{1 0 0 , 0}$ & $\mathbf{7 3 0 . 7 7 8}$ & $\mathbf{1 0 0 , 0}$ \\
\hline
\end{tabular}

Fonte: Censos de 1831-32 e 1838-40 (PAIVA, 1996), mapas de 1833-35 (MARTINS, 1990), dados populacionais de 1826 (CUNHA MATOS, 1979).

\footnotetext{
7 Para relação dos distritos de paz que compõem a Estimativa, com a discriminação do número de habitantes, ver Godoy (2004, apêndice 2, p. 679-697).
} 
nominativas do Censo de 1831-32, segundo a qualidade da informação de ocupação, elaborou-se amostra constituída por distritos quase sempre com elevado padrão informativo.

Embora na definição da amostra tenhase conferido prioridade para inclusão de listas nominativas com elevado padrão informativo, também prevaleceu a preocupação com a mais estrita representatividade regional. Em outros termos, a amostra foi constituída igualmente referenciada na distribuição relativa da população pelas regiões, revelada pela Estimativa Populacional de 1831-35. Em resumo, buscou-se o equilíbrio entre a pontuação das listas nominativas e a proporcionalidade na distribuição da população pelas regiões.

$\mathrm{Na}$ composição da amostra foi possível a larga incorporação de listas nominativas com elevada qualidade da informação de ocupação. Dos 60 distritos selecionados (identificados com asterisco, no Anexo), 50 (ou 83\%) apresentaram classificação acima de $50 \%$ da pontuação (39 a 74 pon- tos), ou $53,2 \%$ das 94 listas nominativas do Censo de 1831-32 classificadas nesta faixa. Apenas dez distritos da amostra (ou 17\%) apresentaram classificação abaixo de $50 \%$ da pontuação (até 33 pontos), ou 6,9\% das 144 listas nominativas do Censo de 1831-32 classificadas nesta faixa.

Ainda em relação ao Censo de 1831-32, os 60 distritos e 113.903 habitantes da amostra representam, respectivamente, pouco mais de um quarto das listas nominativas e quase um terço da população. Se cotejada com a distribuição regional dos distritos da Estimativa Populacional de 1831-35, a amostra apresenta poucas discrepâncias (Tabela 3). Apenas para quatro regiões não foi possível estabelecer a necessária proporção: Sertão, Sertão do Rio Doce, Triângulo e Sertão do Alto São Francisco. Portanto, a amostra corrigiu a maioria das distorções da distribuição relativa dos distritos que compõem o Censo de 1831-32 em relação à Estimativa, que provavelmente resultaram da aleatoriedade das listas nominativas remanescentes.

TABELA 3

Distribuição regional da população da Estimativa, do Censo e da Amostra Minas Gerais - 1831-35

\begin{tabular}{|c|c|c|c|c|c|c|}
\hline \multirow{2}{*}{ Regiões } & \multicolumn{2}{|c|}{ Estimativa 1831-35 } & \multicolumn{2}{|c|}{ Amostra } & \multicolumn{2}{|c|}{ Censo 1831-32 } \\
\hline & N. abs. & $\%$ & N. abs. & $\%$ & N. abs. & $\%$ \\
\hline Vale Alto Médio São Francisco & 14.220 & 1,98 & 1.974 & 1,73 & 2.875 & 0,70 \\
\hline Sertão & 8.726 & 1,21 & 2.690 & 2,36 & 8.747 & 2,14 \\
\hline Minas Novas & 56.242 & 7,83 & 7.611 & 6,68 & 12.979 & 3,18 \\
\hline Paracatu & 10.152 & 1,41 & 1.753 & 1,54 & 2.948 & 0,72 \\
\hline Sertão Alto São Francisco & 18.089 & 2,52 & 2.025 & 1,78 & 5.566 & 1,36 \\
\hline Médio Baixo Rio das Velhas & 35.711 & 4,97 & 5.647 & 4,96 & 19.166 & 4,70 \\
\hline Sertão Rio Doce & 267 & 0,04 & 268 & 0,24 & 268 & 0,07 \\
\hline Triângulo & 10.287 & 1,43 & 2.317 & 2,03 & 3.942 & 0,97 \\
\hline Araxá & 22.006 & 3,06 & 4.021 & 3,53 & 14.704 & 3,61 \\
\hline Intermediária Pitangui-Tamanduá & 83.949 & 11,69 & 13.233 & 11,62 & 54.808 & 13,44 \\
\hline Diamantina & 28.393 & 3,95 & 4.837 & 4,25 & 24.009 & 5,89 \\
\hline Mineradora Central Leste & 33.619 & 4,68 & 4.495 & 3,95 & 17.758 & 4,35 \\
\hline Mineradora Central Oeste & 169.074 & 23,54 & 27.664 & 24,29 & 117.370 & 28,78 \\
\hline Mata & 42.364 & 5,90 & 6.648 & 5,84 & 16.701 & 4,10 \\
\hline Sudeste & 69.098 & 9,62 & 10.358 & 9,09 & 38.170 & 9,36 \\
\hline Sul Central & 88.278 & 12,29 & 14.009 & 12,30 & 47.179 & 11,57 \\
\hline Sudoeste & 27.716 & 3,86 & 4.353 & 3,82 & 20.630 & 5,06 \\
\hline Minas Gerais & 718.191 & 100,00 & 113.903 & 100,00 & 407.820 & 100,00 \\
\hline
\end{tabular}

Fonte: Censos de 1831-32 e 1838-40 (PAIVA, 1996), mapas de 1833-35 (MARTINS, 1990), dados populacionais de 1826 (CUNHA MATOS, 1979). 
A composição da população por condição social e idade, na amostra, não apresentou nenhuma divergência de monta em relação ao Censo de 1831-32. Na primeira, os escravos representam $31,7 \%$ da população e, no Censo de 1831-32, perfazem $33,1 \%$. Como demonstram os Gráficos 1 e 2, a distribuição pelas faixas etárias, tanto para indivíduos livres como para cativos, também não evidenciou distinções relevantes.

\section{Estrutura ocupacional da província de Minas Gerais}

Demonstrada a representatividade da amostra, realizou-se estudo da estrutura ocupacional em três distintos níveis: pro- vincial, regional e distrital. Estabeleceu-se regular cotejo entre a estrutura do Censo de 1831-32, ou a totalidade das listas nominativas remanescentes, e a estrutura da amostra, ou os 60 distritos selecionados. Como referido, buscou-se evidenciar os efeitos da omissão e distorção informativas. Acreditase que a metodologia para a classificação das listas nominativas e a proposição da amostra permitiram consistente aproximação da estrutura ocupacional da província de Minas Gerais, corrigida dos efeitos da grande subenumeração e larga simplificação que predominam na informação de ocupação do Censo de 1831-32. Cabe ainda anotar que todos os resultados compreenderam a população com dez anos e mais, ou com a

GRÁFICO 1

Estrutura etária da população livre e escrava, por sexo, segundo o Censo Minas Gerais - 1831-32

Livres

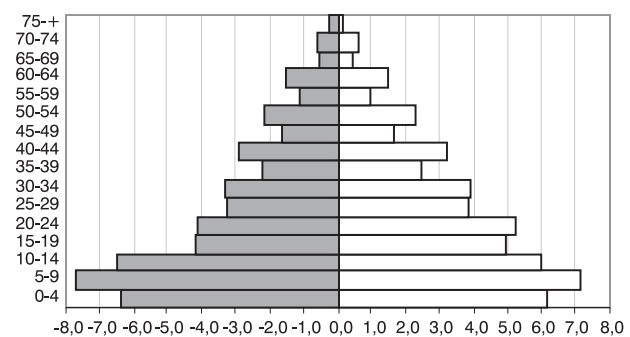

Escravos

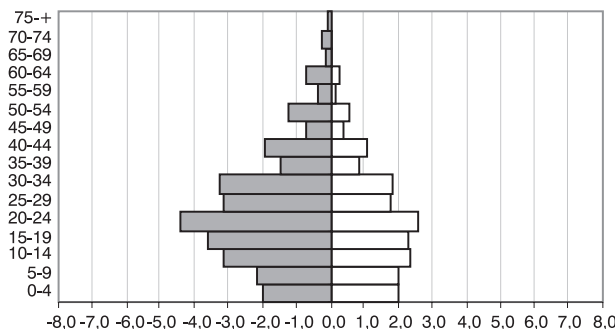

$\square$ Homens $\square$ Mulheres

Fonte: Censo de 1831-32.

GRÁFICO 2

Estrutura etária da população livre e escrava, por sexo, segundo amostra do Censo Minas Gerais - 1831-32

Livres

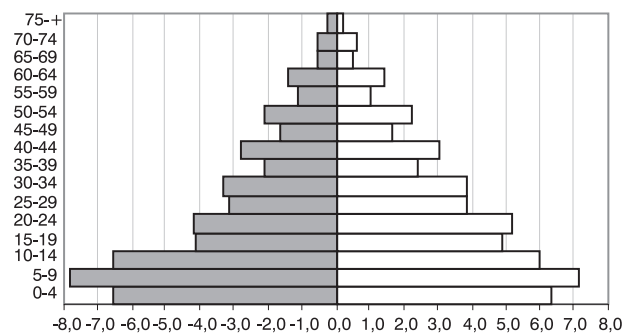

Escravos

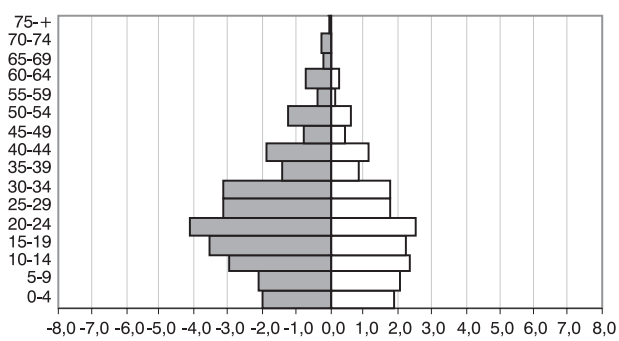

$\square$ Homens $\square$ Mulheres

Fonte: Censo de 1831-32. 
exclusão dos indivíduos das duas primeiras faixas ( 0 a 4 e 5 a 9 anos).

No nível mais agregado, ou considerada toda a província, os resultados salientaram grande diferença entre as estruturas ocupacionais comparadas (Tabela 4). Constatouse que o elevado patamar de não informação, sobretudo para a população escrava, afetou sobremaneira a estrutura ocupacional do Censo de 1831-32. Todos os setores, mais ou menos, apresentaram participação relativa inferior à da estrutura ocupacional da amostra, excetuadas as funções públicas. Entretanto, a omissão e distorção informativas afetaram mais incisivamente determinados setores. Tendo em vista que a não informação de ocupação para a população total da amostra $(17,9 \%)$ é $62,7 \%$ menor do que no Censo de 1831-32 (48,0\%), ressalta-se o impacto diferenciado sobre os setores ocupacionais. Assim, a participação relativa da agropecuária, mineração e atividades manuais e mecânicas apresentou variação mais ou menos correspondente (mais $60 \%, 57 \%$ e $58 \%$, respectivamente), enquanto a do comércio ficou muito abaixo (5\%) e a do serviço doméstico muito acima (157\%) e, como mencionado, as funções públicas apresentaram participação relativa maior no Censo de 1831-32 em relação à amostra (15\%).

O exame dos resultados segmentados por condição social é elucidativo quanto ao significado das variações nas estruturas ocupacionais comparadas. Considerandose que a não informação de ocupação para a população livre da amostra é $56,8 \%$ menor do que no Censo de 1831-32 (17,0\% e $39,4 \%$, respectivamente), verifica-se que as diferenças entre as estruturas comparadas são bem menos importantes do que na população total, conquanto destacadas para as atividades manuais e mecânicas (51\% maior) e serviço doméstico ( $111 \%$ maior). Para a agropecuária e mineração não chegam a um terço para mais (29\% e $21 \%)$, enquanto o comércio apresenta participação relativa praticamente igual (menos $1 \%$ ) e as funções públicas são relativamente mais expressivas no Censo de 1831-32 (menos $15 \%)$. Já para a população escrava, que na amostra apresenta não informação de ocupação $69,4 \%$ menor do que no Censo de $1831-32$ (19,7\% e $64,4 \%$, respectivamente), salientaram-se distinções invariavelmente muito mais pronunciadas do que na população total: os escravos são 125\% mais incidentes na agropecuária, $180 \%$ na mineração, 93\% nas atividades manuais e mecânicas, $99 \%$ no comércio e $180 \%$ no serviço doméstico.

A comparação da participação relativa de livres e escravos evidenciou outras importantes divergências entre a amostra e o Censo de 1831-32. Enquanto no Censo as proporções de livres e escravos na agropecuária não são muito diferentes $(19,5 \%$ e $17,3 \%$, respectivamente, ou $11,0 \%$ a menos para os cativos), na amostra não somente a participação de escravos é maior $(39,1 \%)$, como supera a dos livres $(25,2 \%)$ em $55,2 \%$. Da mesma forma, se no Censo as proporções de livres e cativos na mineração não apresentam distinção acentuada (1,6\% e $1,9 \%$, respectivamente, ou $18,3 \%$ a mais para os escravos), na amostra a participação relativa de cativos é bem maior (1,3\% e 5,4\%, ou $315,4 \%$ superior).

Em termos absolutos, o problema da qualidade da informação de ocupação para os escravos apresentou-se de forma incontrastável, como quando se constatou que, embora a população cativa da amostra represente $28,2 \%$ daquela registrada no Censo de 1831-32 (29.844 para 105.909), os escravos na mineração da amostra perfizeram $78,9 \%$ dos cativos do Censo de $1831-32,63,5 \%$ da agropecuária, $54,3 \%$ das atividades manuais e mecânicas, $56,1 \%$ do comércio e $78,9 \%$ do serviço doméstico.

Em síntese, a comparação das estruturas ocupacionais revelou que os efeitos da omissão e distorção informativas alteraram sobremaneira a qualidade da variável ocupação no Censo de 1831-32 e, além de reduzir substantivamente a participação relativa de quase todos os setores, responderam por específicas modificações na estrutura ocupacional, como na particular acentuada redução da participação de escravos na mineração e no geral esvaziamento da importância do serviço doméstico. Entretanto, em outro sentido, a incidência seletiva do problema da qualidade da informação também 
foi demonstrada com o efeito relativamente reduzido sobre as funções públicas. Assim, pode-se afirmar que a omissão informativa repercutiu de forma assimétrica sobre os setores ocupacionais, indicando, de forma inequívoca, que também a distorção informativa deve ser considerada.

A estrutura revelada pela amostra sobrelevou a diversificação ocupacional da população total, ainda que marcada pelo predomínio da agropecuária e das atividades manuais e mecânicas. Para a população livre, a proeminência desses setores era ainda maior, conquanto o comércio respondesse por posição mais expressiva do que na população total. Para os escravos, observou-se inversão na posição relativa dos maiores setores, com a agropecuária perfazendo quase o dobro da participação das atividades manuais e mecânicas, além da significativa importância da mineração e, principalmente, do serviço doméstico.

Do nível provincial para o regional, examina-se agora a estrutura ocupacional da região Mineradora Central Oeste (Tabela 5). A escolha justifica-se pela incontrastável importância demográfica e econômica da região (PAIVA, 1996; GODOY, 1996), por compreender o espaço mais importante da economia do ouro do século XVIII (VENÂN$\mathrm{CIO}, 2001$ ) e por deter a mais desenvolvida malha urbana da província (RODARTE, 1999).

A análise das estruturas ocupacionais regionais comparadas convergiu para constatações muito próximas das salientadas quando da apreciação das estruturas provinciais. A participação relativa dos setores, excetuadas as funções públicas, apresentou-se subestimada na base de

TABELA 4

Estrutura ocupacional da população livre e escrava no Censo e na amostra, segundo setores de atividade Minas Gerais - 1831-32

\begin{tabular}{|c|c|c|c|c|c|c|c|c|c|c|c|c|}
\hline \multirow{3}{*}{ Setores } & \multicolumn{6}{|c|}{ Censo 1831-32 } & \multicolumn{6}{|c|}{ Amostra } \\
\hline & \multicolumn{2}{|c|}{ Livres } & \multicolumn{2}{|c|}{ Escravos } & \multicolumn{2}{|c|}{ Total } & \multicolumn{2}{|c|}{ Livres } & \multicolumn{2}{|c|}{ Escravos } & \multicolumn{2}{|c|}{ Total } \\
\hline & N. abs. & $\%$ & N. abs. & $\%$ & N. abs. & $\%$ & N. abs. & $\%$ & N. abs. & $\%$ & N. abs. & $\%$ \\
\hline Sem informação & 7.638 & 39,2 & 8.200 & 64,4 & 145.838 & 48,0 & .495 & 17,0 & 5.889 & 19,7 & 15.384 & 17,9 \\
\hline Agropecuária & 38.562 & 19,5 & 18.368 & 17,3 & 56.930 & 18,7 & 14.095 & 25,2 & 11.668 & 39,1 & 25.763 & 30,0 \\
\hline Miner & 246 & 1,64 & 2.055 & 1,9 & 301 & 1,8 & 729 & 1,3 & 1.622 & 5,4 & 2.351 & 2,7 \\
\hline $\begin{array}{l}\text { Ativida } \\
\text { e mec }\end{array}$ & 54.950 & 27,8 & 11.311 & 10,7 & 66.261 & 21,8 & 23.436 & 41,9 & 6.140 & 20,6 & 29.576 & 34,5 \\
\hline Comércio & 6.450 & 3,3 & 401 & 0,4 & 6.851 & 2,3 & 1.801 & 3,2 & 225 & 0,8 & 2.026 & 2,4 \\
\hline Serviço dom & 1.818 & 0,9 & 3.819 & 3,6 & 5.637 & 1,9 & 1.087 & 1,9 & 3.012 & 10,1 & 4.099 & 4,8 \\
\hline Funçã & 58 & 0,5 & 0 & 0 & 58 & 0,4 & 255 & 0,5 & 0 & 0 & 255 & 0,3 \\
\hline Outras atividades & 11.553 & 5,8 & 1.488 & 1,4 & 13.041 & 4,3 & 3.883 & 6,9 & 1.104 & 3,7 & 4.987 & 5,8 \\
\hline Desocupados & 1.653 & 0,8 & 121 & 0,1 & 1.774 & 0,6 & 741 & 1,3 & 75 & 0,3 & 816 & 1,0 \\
\hline $\begin{array}{l}\text { Associações } \\
\text { ocupacionais }\end{array}$ & 929 & 0,5 & 146 & 0,1 & 1.075 & 0,4 & 466 & 0,8 & 109 & 0,4 & 575 & 0,7 \\
\hline Total & 197.857 & 100,0 & 105.909 & 100,0 & 303.766 & 100,0 & 55.988 & 100,0 & 29.844 & 100,0 & 85.832 & 100,0 \\
\hline
\end{tabular}

Fonte: Censo de 1831-32

Nota: Nas listas nominativas que compõem o Censo de 1831-32, não é possível distinguir a não frequência de informação da omissão informativa. Em outros termos, as autoridades locais responsáveis pelo arrolamento da população não adotaram critério único e perfeitamente discernível para assinalar a ausência de determinado atributo e, por decorrência, distingui-lo da simples falta da informação. Assim, não é possível determinar sempre e, na maior parte dos casos, com segurança quando a ausência da informação é: i. indisponibilidade de informação (desconhecida pelo recenseador e/ou não disponibilizada pelo recenseado); ii. não pertinência de atributo específico (não detentor de determinada característica, por não se aplicar); iii. omissão de informação por parte do recenseador (o recenseador conhece ou lhe foi declarada a informação, conquanto este não arrole o dado). Assim, nas tabelas 4, 5 e 6 deve-se considerar o zero ausência de frequência, excetuada para a categoria "sem informação", que compreende, indistintamente, os casos de indisponibilidade da informação, aqueles em que não se aplicam os caracteres recenseados e os casos de omissão de informação. Portanto, não é possível distinguir o que é zero real do que é falta de informação. Do mesmo modo, entende-se que o estudo da qualidade da informação em censos históricos é o melhor caminho para minimizar os efeitos desta indeterminação. 
dados do Censo de 1831-32 em relação à da amostra.

Posto que a não informação de ocupação para a população total da amostra $(12,6 \%)$ é $69,4 \%$ menor do que no Censo de 1831-32 (41,3\%), destacam-se distintas repercussões sobre os setores ocupacionais. Dessa forma, as participações da agropecuária, das atividades manuais e mecânicas e do comércio ficaram abaixo da variação da informação de ocupação (mais $36,7 \%, 38,9 \%$ e $15,6 \%$, respectivamente), as da mineração e do serviço doméstico muito acima (mais 129,3\% e 194,9\%) e as funções públicas apresentaram, como no caso da comparação das estruturas ocupacionais provinciais, participação maior no Censo de 1831-32 do que em relação à amostra $(28,9 \%)$. Portanto, também para a estrutura ocupacional da população total da região Mineradora Central Oeste, repetiram-se acentuadas divergências que sobrelevaram impactos diferenciados da omissão e distorção informativas.

Segmentada a população por condição social, ganharam projeção determinadas variações nas estruturas ocupacionais comparadas. Visto que a não informação de ocupação para a população livre da amostra é $57,5 \%$ menor do que no Censo de 1831-32 (13,4\% e $31,6 \%$, respectivamente), constatou-se que, como no caso da comparação das estruturas provinciais, as divergências entre as estruturas regionais comparadas dos livres são bem menos significativas do que na população total, ainda que mais expressivas para a mineração (52,8\% maior) e, principalmente, serviço doméstico (120,0\% maior). Para as atividades manuais e mecânicas, a diferença pouco ultrapassou em um terço $(35,7 \%)$, a agropecuária e o comércio quase mantiveram a mesma participação relativa (1,1\% e $4,2 \%$ maior) e as funções públicas, novamente, apresentaram-se relativamente mais expressivas no Censo de 1831-32 (menos 28,9\%). Como no cotejo entre as estruturas provinciais, para a população escrava da região Mineradora Central Oeste, que na amostra apresentou não informação de ocupação $80,8 \%$ menor do que no Censo de $1831-32$ (11,2\% e 58,2\%, respectivamente), verificaram-se distinções quase sempre muito mais pronunciadas do que na população total. O confronto dos resultados da amostra com os do Censo de 1831-32 revelou que os cativos são $215,1 \%$ mais incidentes na mineração, 132,1\% no comércio e $120,0 \%$ no serviço doméstico. $\mathrm{Na}$ agropecuária, a diferença ficou um pouco acima da variação da incidência de informação de ocupação (mais 90,5\%) e nas atividades manuais e mecânicas bem abaixo (mais $44,4 \%$ ).

O cotejo da participação de livres e escravos sobrelevou outras distinções relevantes entre a amostra e o Censo de 1831-32. $\mathrm{Se}$, no Censo, a diferença na proporção de livres (13,3\%) e cativos (16,8\%) na agropecuária não ganhava muita expressão $(26,3 \%$ a mais para os escravos), na amostra ficava evidente a larga predominância relativa dos cativos $(13,5 \%$ e $32,0 \%$, respectivamente, ou $137 \%$ a mais para os escravos). $\mathrm{Na}$ mineração a divergência das estruturas comparadas alcançou patamar ainda maior. Se, no Censo, a proporção de livres (2,3\%) e escravos $(4,0 \%)$ na mineração era bem distinta (73,9\% a mais de cativos), na amostra acentua-se muito mais a diferença $(3,5 \%$ e $12,7 \%$, respectivamente, ou $262,9 \%$ a mais de escravos).

Como no caso das estruturas ocupacionais provinciais comparadas, do cotejo dos números absolutos do Censo de 1831-32 com os da amostra sobressaíram inequívocas evidências dos comprometimentos decorrentes do problema da qualidade da informação de ocupação, mormente para os escravos. Assim, conquanto a população cativa da amostra (7.767) representasse $22,8 \%$ daquela registrada no Censo (34.083), os escravos na mineração da amostra perfaziam $71,8 \%$ dos cativos do Censo de 1831 $32,75,2 \%$ do serviço doméstico, $52,9 \%$ do comércio e 43,4\% da agropecuária.

As conclusões são as mesmas quando da análise do cotejo das estruturas ocupacionais da província: elevada influência da omissão e da distorção informativas na qualidade da variável ocupação do Censo de 1831-32, tendendo à redução da participação relativa de quase todos os setores, com repercussão mais incisiva sobre determinados setores e faixas de população e 
preservação de certas categorias ocupacionais e segmentos populacionais.

A amostra evidenciou que a região Mineradora Central Oeste apresentava estrutura ocupacional diversificada, em que pese que as atividades manuais e mecânicas e a agropecuária respondessem, juntas, por mais da metade da ocupação de livres e escravos. A mineração ainda era atividade expressiva, sobretudo para a população cativa, o comércio constituía atividade eminentemente desenvolvida por indivíduos livres e o serviço doméstico era o terceiro setor com maior grau de emprego de escravos.

O último movimento ou etapa da análise da estrutura ocupacional destinou-se à comparação de duas listas remanescentes do Censo de 1831-32. Para respeitar procedimento de desagregação, em que o nível inferior sempre está contido no nível superior, foram escolhidos dois distritos da região Mineradora Central Oeste. Selecionaram-se distritos geograficamente próximos (com sedes a menos de 40 quilômetros de distância) e com evoluções históricas semelhantes, ambas localidades originalmente mineradoras e que se formaram no início do século XVIII (BARBOSA, 1971, p. 25 e 320). Congonhas do Sabará ainda não havia recebido o impacto do estabelecimento de grande mineradora estrangeira - a Companhia Saint John d'El Rey Mining Company iniciou suas atividades na Mina do Morro Velho em 1834 (LIBBY, 1984, p. 16) - e apresentava, em 1818, segundo Saint-Hilaire, quadro de "decadência e abandono". 8 Rio de Pedras encontrava-se no mesmo estado de "decadência" e as condições urbanas impressionavam pelo elevado grau de deterioração. ${ }^{9}$

TABELA 5

Estrutura ocupacional da população livre e escrava no Censo e na amostra, segundo setores de atividade Região Mineradora Central Oeste - 1831-32

\begin{tabular}{|c|c|c|c|c|c|c|c|c|c|c|c|c|}
\hline \multirow{3}{*}{ Setores } & \multicolumn{6}{|c|}{ Censo 1831-32 } & \multicolumn{6}{|c|}{ Amostra } \\
\hline & \multicolumn{2}{|c|}{ Livres } & \multicolumn{2}{|c|}{ Escravos } & \multicolumn{2}{|c|}{ Total } & \multicolumn{2}{|c|}{ Livres } & \multicolumn{2}{|c|}{ Escravos } & \multicolumn{2}{|c|}{ Total } \\
\hline & N. abs. & $\%$ & N. abs. & $\%$ & N. abs. & $\%$ & N. abs. & $\%$ & N. abs. & $\%$ & N. abs. & $\%$ \\
\hline Sem Informação & 18.665 & 31,6 & 19.827 & 58,2 & 38.492 & 41,3 & 1.933 & 13,4 & 868 & 11,2 & 2.801 & 12,6 \\
\hline Agropecuária & 7.885 & 13,3 & 5.721 & 16,8 & 13.606 & 14,6 & 1.942 & 13,5 & 2.483 & 32,0 & 4.425 & 20,0 \\
\hline Mineração & 1.365 & 2,3 & 1.369 & 4,0 & 2.734 & 2,9 & 508 & 3,5 & 983 & 12,7 & 1.491 & 6,7 \\
\hline $\begin{array}{l}\text { Atividades manuais } \\
\text { e mecânicas }\end{array}$ & 22.040 & 37,3 & 4.433 & 13,0 & 26.473 & 28,4 & 7.284 & 50,6 & 1.459 & 18,8 & 8.743 & 39,4 \\
\hline Comércio & 2.691 & 4,6 & 225 & 0,7 & 2.916 & 3,1 & 683 & 4,7 & 119 & 1,5 & 802 & 3,6 \\
\hline Serviço doméstico & 461 & 0,8 & 1.502 & 4,4 & 1.963 & 2,1 & 247 & 1,7 & 1.130 & 14,5 & 1.377 & 6,2 \\
\hline Funções públicas & 491 & 0,8 & 0 & 0,0 & 491 & 0,5 & 83 & 0,6 & 0 & 0,0 & 83 & 0,4 \\
\hline Outras atividades & 4.521 & 7,6 & 918 & 2,7 & 5.439 & 5,8 & 1.346 & 9,3 & 686 & 8,8 & 2.032 & 9,2 \\
\hline Desocupados & 663 & 1,1 & 48 & 0,1 & 711 & 0,8 & 268 & 1,9 & 31 & 0,4 & 299 & 1,3 \\
\hline $\begin{array}{l}\text { Associações } \\
\text { ocupacionais }\end{array}$ & 319 & 0,5 & 40 & 0,1 & 359 & 0,4 & 102 & 0,7 & 8 & 0,1 & 110 & 0,5 \\
\hline Total & 59.101 & 100 & 34.083 & 100 & 93.184 & 100 & 14.396 & 100 & 7.767 & 100 & 22.163 & 100 \\
\hline
\end{tabular}

Fonte: Censo de 1831-32.

\footnotetext{
8 "À cerca de três léguas, na direção S. W. de Sabará, passei pela aldeia de Congonhas de Sabará, cabeça de paróquia cuja população ascende a 1.390 indivíduos. É ela situada em uma baixada, a 1920' lat. S., 3326' long., a 14 léguas de Mariana e 96 léguas do Rio de Janeiro. Sua igreja, isolada como geralmente adota-se neste país, é construída a uma das extremidades de uma praça muito regular, em forma de um longo quadrilátero. Congonhas deve sua fundação a mineradores atraídos pelo ouro que se encontrava em seus arredores, e sua história é a mesma de tantas outras aldeias. O precioso metal esgotou-se; os trabalhos tornaram-se difíceis e Congonhas atualmente apresenta decadência e abandono" (SAINT-HILAIRE, 1974, p. 78).

9 "À cerca de três léguas de Cocho de Água passei pela aldeia de Rio de Pedras, situada sobre um outeiro acima do rio que lhe dá nome. A igreja, que é construída entre duas fileiras de palmeiras, avista-se de longe e empresta um belo efeito à paisagem. Depois que me pusera em marcha não vira senão localidades em decadência; mas não vira também nenhuma em tão mau estado quanto Rio de Pedras. A maioria das casas desta aldeia foram construídas com cuidado, mas acham-se atualmente desertas ou em ruínas. Como Congonhas e Santo Antônio, Rio de Pedras é a cabeça de uma paróquia; assim, em um espaço de apenas 9 léguas atravessei três paróquias, o que prova quanto esta região, hoje quase abandonada, foi outrora populosa [segundo Pizarro, Rio das Pedras, ou N. S. ${ }^{a}$ da Conceição de Rio de Pedras fica a 8 Is. de Mariana e 86 do Rio de Janeiro, a 2013' lat. e 333ㅇ24' long., com 1.200 habitantes]" (SAINT-HILAIRE, 1974, p. 79).
} 
Assim, presume-se que pouco mais de uma década depois, quando da realização do Censo de 1831-32, Congonhas do Sabará e Rio de Pedras apresentavam quadros demográfico e econômico inalterados. Os distritos muito provavelmente se inscreviam em processo que abarcava grande parte das localidades da região Mineradora Central Oeste. Processo marcado por reestruturação produtiva em estágio avançado, expresso em mineração pouco dinâmica e crescimento da agropecuária e atividades de transformação em geral (artesanato e manufatura), que, em larga medida, baseavam-se no trabalho escravo (GODOY, 1996, p. 62-66).

Os dados apresentados na sequência reafirmam estas características, conquanto permitam conhecimento muito mais refinado da estrutura ocupacional dos distritos (Tabela 6). Entretanto, o objetivo precípuo da comparação dos dados de Congonhas do Sabará com os de Rio de Pedras é demonstrar o quanto o problema da qualidade da informação pode comprometer o conhecimento da estrutura ocupacional, assim como de qualquer variável demográfica.

A primeira impressão do cotejo das estruturas ocupacionais é de que a omissão e distorção informativas comprometeram severamente os resultados. Se aceito o pressuposto de que esses pequenos distritos deveriam apresentar estruturas ocupacionais semelhantes, a assimetria da qualidade da informação de ocupação responde então pelas grandes divergências assinaláveis. A omissão é evidente, visto que os responsáveis pela lista de Rio de Pedras não informaram a ocupação para a população escrava. A distorção é presumível como decorrência da ausência de frequência ou relativa baixa incidência para vários grupos ocupacionais no arrolamento de Rio de Pedras em relação ao de Congonhas do Sabará.

Da análise dos números absolutos, despontam divergências que só se explicam por distintos padrões informativos. Embora a população livre de Rio de Pedras (580 pessoas) fosse $17,6 \%$ superior à de Congonhas do Sabará (478), para a maioria dos grupos ocupacionais o número de indivíduos livres listados em Rio de Pedras era menor, quan- do não sem frequência. Assim, por exemplo, parece insustentável supor a inexistência, em Rio de Pedras, de indivíduos livres inseridos em atividades domésticas, no comércio de tropas, no controle do trabalho escravo e em atividades de transporte.

Considerada a omissão completa da ocupação dos cativos de Rio de Pedras, bem como o elevado patamar de informação para escravos de Congonhas do Sabará (89,3\%), depreende-se que o segundo caso pode iluminar o primeiro. Em outros termos, propõe-se conhecer a estrutura ocupacional de Rio de Pedras pela de Congonhas do Sabará. É possível afirmar que o extremo da omissão das autoridades responsáveis pelo arrolamento da população escrava de Rio de Pedras impediu que se conhecesse a estrutura ocupacional marcada pela concentração dos cativos em quatro setores ocupacionais (agropecuária, mineração, atividades manuais e mecânicas e serviço doméstico), além da presença em outros setores, como no comércio. Em perfeita consonância com o mencionado estágio avançado do processo de reestruturação produtiva, em curso desde a segunda metade do século XVIII, a concentração do trabalho escravo na mineração foi substituída, gradualmente, pelo emprego do trabalho compulsório em múltiplas atividades.

Longe do quadro assinalado pelo ilustre viajante francês, a ponderável participação de escravos na população dos antigos centros mineradores $(30,9 \%$ em Congonhas do Sabará e 23,5\% em Rio de Pedras) é indício de economias locais vigorosas o suficiente para se lastrearem em significativo recurso ao trabalho cativo. A expressiva participação relativa do setor comercial, entre negociantes estabelecidos e tropeiros, sugere atividades agropecuárias em alguma medida integradas ao mercado, certamente a fonte dos recursos que permitiam a recomposição, ou mesmo ampliação, da população mancípia. Como asseverou Roberto Martins, a miopia de importante parcela dos contemporâneos, nativos e adventícios, e também daqueles que se dedicaram ao estudo da história da província de Minas Gerais, pelo menos até a década de 1980, decorreu da incompreensão do caráter da economia 
mineira do século XIX. A pouca visibilidade de atividades orientadas para o mercado interno foi equivocadamente interpretada como estagnação, quando não como decadência (MARTINS, 1982). Não considerar os problemas da informação de ocupação no Censo de 1831-32, o mais importante repositório de dados sociodemográficos e econômicos, para a primeira metade do século XIX, pode significar a perda de in- substituível oportunidade de ampliação do conhecimento sobre a economia e sociedade mineiras do período provincial.

\section{Considerações finais}

Releva concluir que os graves problemas decorrentes da omissão e distorção informativas, que prevaleceram no recolhimento e registro dos dados do Censo de

TABELA 6

Estrutura ocupacional da população livre e escrava, segundo setores de atividade Distritos de Congonhas do Sabará e Rio de Pedras - 1831-32

\begin{tabular}{|c|c|c|c|c|c|c|c|c|c|c|c|c|}
\hline \multirow{3}{*}{$\begin{array}{l}\text { Setores e grupos } \\
\text { ocupacionais }\end{array}$} & \multicolumn{6}{|c|}{ Congonhas do Sabará } & \multicolumn{6}{|c|}{ Rio de Pedras } \\
\hline & \multicolumn{2}{|c|}{ Livres } & \multicolumn{2}{|c|}{ Escravos } & \multicolumn{2}{|c|}{ Total } & \multicolumn{2}{|c|}{ Livres } & \multicolumn{2}{|c|}{ Escravos } & \multicolumn{2}{|c|}{ Total } \\
\hline & N. abs. & $\%$ & N. abs. & $\%$ & N. abs. & $\%$ & N. abs. & $\%$ & N. abs. & $\%$ & N. abs. & $\%$ \\
\hline Sem Informação & 130 & 27,2 & 23 & 10,7 & 153 & 22,1 & 331 & 57,1 & 178 & 100 & 509 & 67,2 \\
\hline Agropecuária & 21 & 4,4 & 47 & 22,0 & 68 & 9,8 & 19 & 3,3 & 0 & 0,0 & 19 & 2,5 \\
\hline Agricultura & 14 & 2,9 & 43 & 20,1 & 57 & 8,2 & 18 & 3,1 & 0 & 0,0 & 18 & 2,4 \\
\hline Agroindústria & 1 & 0,2 & 1 & 0,5 & 2 & 0,3 & 0 & 0,0 & 0 & 0,0 & 0 & 0,0 \\
\hline Pecuária & 5 & 1,0 & 1 & 0,5 & 6 & 0,9 & 1 & 0,2 & 0 & 0,0 & 1 & 0,1 \\
\hline Mineração & 35 & 7,3 & 38 & 17,8 & 73 & 10,5 & 27 & 4,7 & 0 & 0,0 & 27 & 3,6 \\
\hline $\begin{array}{l}\text { Atividades manuais e } \\
\text { mecânicas }\end{array}$ & 198 & 41,4 & 46 & 21,5 & 244 & 35,3 & 107 & 18,4 & 0 & 0,0 & 107 & 14,1 \\
\hline Madeira & 7 & 1,5 & 0 & 0,0 & 7 & 1,0 & 9 & 1,6 & 0 & 0,0 & 9 & 1,2 \\
\hline Metais & 20 & 4,2 & 1 & 0,5 & 21 & 3,0 & 18 & 3,1 & 0 & 0,0 & 18 & 2,4 \\
\hline Couro e peles & 10 & 2,1 & 5 & 2,3 & 15 & 2,2 & 5 & 0,9 & 0 & 0,0 & 5 & 0,7 \\
\hline Barro & 1 & 0,2 & 0 & 0,0 & 1 & 0,1 & 0 & 0,0 & 0 & 0,0 & 0 & 0,0 \\
\hline Tecidos & 23 & 4,8 & 4 & 1,9 & 27 & 3,9 & 10 & 1,7 & 0 & 0,0 & 10 & 1,3 \\
\hline Fiação e tecelagem & 128 & 26,8 & 34 & 15,9 & 162 & 23,4 & 63 & 10,9 & 0 & 0,0 & 63 & 8,3 \\
\hline Construção civil & 5 & 1,0 & 0 & 0,0 & 5 & 0,7 & 2 & 0,3 & 0 & 0,0 & 2 & 0,3 \\
\hline Outras & 4 & 0,8 & 2 & 0,9 & 6 & 0,9 & 0 & 0,0 & 0 & 0,0 & 0 & 0,0 \\
\hline Comércio & 35 & 7,3 & 6 & 2,8 & 41 & 5,9 & 31 & 5,3 & 0 & 0,0 & 31 & 4,1 \\
\hline Comércio fixo & 27 & 5,6 & 1 & 0,5 & 28 & 4,0 & 31 & 5,3 & 0 & 0,0 & 31 & 4,1 \\
\hline Comércio de tropas & 8 & 1,7 & 5 & 2,3 & 13 & 1,9 & 0 & 0,0 & 0 & 0,0 & 0 & 0,0 \\
\hline Serviço doméstico & 20 & 4,2 & 41 & 19,2 & 61 & 8,8 & 0 & 0,0 & 0 & 0,0 & 0 & 0,0 \\
\hline Funções públicas & 4 & 0,8 & 0 & 0,0 & 4 & 0,6 & 2 & 0,3 & 0 & 0,0 & 2 & 0,3 \\
\hline Outras atividades & 29 & 6,1 & 12 & 5,6 & 41 & 5,9 & 51 & 8,8 & 0 & 0,0 & 51 & 6,7 \\
\hline Extrativismo & 0 & 0,0 & 10 & 4,7 & 10 & 1,4 & 2 & 0,3 & 0 & 0,0 & 2 & 0,3 \\
\hline Assalariados & 0 & 0,0 & 1 & 0,5 & 1 & 0,1 & 47 & 8,1 & 0 & 0,0 & 47 & 6,2 \\
\hline Controle trabalho escravo & 4 & 0,8 & 0 & 0,0 & 4 & 0,6 & 0 & 0,0 & 0 & 0,0 & 0 & 0,0 \\
\hline Educação & 5 & 1,0 & 0 & 0,0 & 5 & 0,7 & 0 & 0,0 & 0 & 0,0 & 0 & 0,0 \\
\hline Saúde & 3 & 0,6 & 0 & 0,0 & 3 & 0,4 & 0 & 0,0 & 0 & 0,0 & 0 & 0,0 \\
\hline Transportes & 5 & 1,0 & 1 & 0,5 & 6 & 0,9 & 2 & 0,3 & 0 & 0,0 & 2 & 0,3 \\
\hline Outras atividades & 12 & 2,5 & 0 & 0,0 & 12 & 1,7 & 0 & 0,0 & 0 & 0,0 & 0 & 0,0 \\
\hline Desocupados & 6 & 1,3 & 1 & 0,5 & 7 & 1,0 & 12 & 2,1 & 0 & 0,0 & 12 & 1,6 \\
\hline Total & 478 & 100,0 & 214 & 100,0 & 692 & 100,0 & 580 & 100,0 & 178 & 100,0 & 758 & 100,0 \\
\hline
\end{tabular}

Fonte: Censo de 1831-32. 
1831-32, não podem ser desconsiderados. O estudo da estrutura ocupacional em três níveis de agregação (provincial, regional e distrital) orientou-se precipuamente para a mensuração do grau e extensão do comprometimento da estrutura ocupacional quando examinada sem a imprescindível avaliação da qualidade da informação censitária.

Constatou-se certa seletividade no arrolamento da informação de ocupação, que não apenas reduziu, consideravelmente, a participação relativa de certas categorias, notadamente quando referentes à população escrava, mas também tendeu a superestimar a posição de alguns setores e grupos ocupacionais, como no caso das funções públicas. Portanto, os recenseadores da província, muito mais que omitir dados ocupacionais, parecem ter se inclinado para a alteração, consciente ou inconscientemente, do peso relativo das ocupações arroladas.

Acredita-se que ficou evidente que o problema da qualidade da informação de ocupação não pode ser olvidado em qual-

\section{Referências}

ARQUIVO PÚBLICO MINEIRO. Seção Provincial. Presidência da Província. Mapas de população. Censo de 1831/32. SPPP1/10 e MP, diversas caixas.

BARBOSA, W. de A. Dicionário históricogeográfico de Minas Gerais. Belo Horizonte: Editora Saterb, 1971.

CANO, W. Desequilíbrios regionais e concentração industrial no Brasil: 1930-1970. São Paulo: Global; Campinas: Editora da Unicamp, 1985.

CUNHA MATOS, R. J. Corografia histórica da província de Minas Gerais (1837). Belo Horizonte: Publicações do Arquivo Público Mineiro, n. 3, 1979.

FERNÁNDEZ, R. V. G. A consistência das listas nominativas de habitantes da capitania de São Paulo: um estudo de caso. Estudos Econômicos, São Paulo: IPE-USP, v.19, n.13, p. 477-496, set./dez. 1989. quer nível de agregação que se considere. Não parece importar se o objetivo é conhecer a estrutura ocupacional da província, de regiões ou de distritos. Em qualquer nível a omissão e distorção informativas comprometeram os resultados a ponto de inverter a participação relativa de setores e grupos, esvaziar a importância de certas categorias e superestimar o peso de outras.

Também se espera que a proposta de classificação das listas nominativas do Censo de 1831-32, segundo a qualidade da informação de ocupação, possa se constituir em referência para orientar futuras investigações. Não se nutre a expectativa de que a proposta apresentada e testada encerre a discussão sobre o tema, no sentido de determinar classificação definitiva. Ao contrário, se assume a perspectiva de que a proposta de classificação, sobretudo pelos riscos inerentes às proposições pioneiras, importa mais pela intenção de contribuir para elevar para outro nível de consistência e potencial explicativo o debate e o trabalho com dados do período pré-censitário.

GODOY, M. M. Intrépidos viajantes e a construção do espaço - Uma proposta de regionalização para as Minas Gerais do século XIX. Belo Horizonte: Cedeplar/UFMG, 1996 (Texto para discussão, n. 109).

No país das minas de ouro a paisagem vertia engenhos de cana e casas de negócio - Um estudo das atividades agroaçucareiras tradicionais mineiras, entre o Setecentos e o Novecentos, e do complexo mercantil da província de Minas Gerais. Tese (Doutorado). São Paulo: FFLCH/USP, 2004.

LIBBY, D. C. Trabalho escravo e capital estrangeiro no Brasil: o caso de Morro Velho. Belo Horizonte: Editora Itatiaia, 1984.

MARTINS, M. do C. S. Revisitando a província - comarcas, termos, distritos e população de Minas Gerais em 1833-35. In: V SEMINÁRIO SOBRE A ECONOMIA MINEIRA. Anais... Diamantina: Cedeplar/UFMG, 1990, p. 13-29. 
MARTINS, R. B. A economia escravista de Minas Gerais no século XIX. Belo Horizonte: Cedeplar/UFMG, 1982 (Texto para discussão, n. 10).

NOZOE, N. H.; COSTA, I. del N. da. Achegas para a qualificação das listas nominativas. Estudos Econômicos, São Paulo, IPE-USP, v. 21, n. 2, p. 271-284, maio/ago. 1991.

PAIVA, C. A.; GODOY, M. M. Território de contrastes: economia e sociedade das Minas Gerais do século XIX. In: SILVA, F. C. T.; MATTOS, H. M.; FRAGOSO, J. (Orgs.). Escritos sobre história e educação homenagem à Maria Yedda Leite Linhares. Rio de Janeiro: Mauad e Faperj, 2001, p. 479-515.
PAIVA, C. A. População e economia das Minas Gerais do século XIX. Tese (Doutorado). São Paulo: FFLCH-USP, 1996.

RODARTE, M. M. S. A pertinácia das minas que não se esgotaram. Dissertação (Mestrado). Belo Horizonte: Cedeplar/ UFMG, 1999.

SAINT-HILAIRE, A. de. Segunda viagem do Rio de Janeiro a Minas Gerais e São Paulo. Belo Horizonte: Itatiaia; São Paulo: Edusp, 1974.

VENÂNCIO, R. P. Comércio e fronteira em Minas Gerais colonial. In: FURTADO, J. F. (Org.). Diálogos oceânicos. Belo Horizonte: Editora da UFMG, 2001, p. 181-182. 


\section{Anexo}

Classificação das listas nominativas do Censo de 1831-32, segundo a qualidade da informação de ocupação

\begin{tabular}{|c|c|c|c|c|c|c|c|c|c|}
\hline $\begin{array}{l}\text { Código } \\
\text { Região }\end{array}$ & $\begin{array}{l}\text { Código } \\
\text { Município }\end{array}$ & $\begin{array}{l}\text { Código } \\
\text { Distrito }\end{array}$ & Região & Município & Distrito & População & $\begin{array}{l}\text { População } \\
\text { com } \\
\text { informação } \\
\text { de ocupação } \\
(\%)\end{array}$ & $\begin{array}{c}\text { № de } \\
\text { ocupações } \\
\text { com } \\
\text { frequência }\end{array}$ & \\
\hline 14 & 08 & 01 & $\begin{array}{l}\text { Miner. Central } \\
\text { Oeste }\end{array}$ & Ouro Preto & $\begin{array}{c}\text { Cachoeira do } \\
\text { Campo* }\end{array}$ & 01476 & 77,8 & 110 & 74 \\
\hline 17 & 04 & 06 & Sul Central & Campanha & $\begin{array}{c}\text { Vila de } \\
\text { Campanha* }\end{array}$ & 05500 & 76,2 & 104 & 72 \\
\hline 14 & 03 & 13 & $\begin{array}{l}\text { Miner. Central } \\
\text { Oeste }\end{array}$ & Caeté & $\begin{array}{l}\text { Vila de } \\
\text { Caeté* }\end{array}$ & 02855 & 74,7 & 104 & 72 \\
\hline 14 & 06 & 38 & $\begin{array}{l}\text { Miner. Central } \\
\text { Oeste }\end{array}$ & Mariana & Catas Altas* & 02089 & 80,6 & 063 & 71 \\
\hline 18 & 05 & 07 & Sudoeste & Jacuí & $\begin{array}{l}\text { São José e } \\
\text { Dores* }\end{array}$ & 03026 & 70,0 & 127 & 69 \\
\hline 07 & 12 & 20 & $\begin{array}{l}\text { Médio Baixo } \\
\text { R. Velhas }\end{array}$ & Sabará & Santa Luzia* & 04230 & 70,0 & 097 & 69 \\
\hline 14 & 03 & 12 & $\begin{array}{l}\text { Miner. Central } \\
\text { Oeste }\end{array}$ & Caeté & $\begin{array}{c}\text { Itabira do } \\
\text { Mato Dentro* }\end{array}$ & 07965 & 64,6 & 114 & 69 \\
\hline 04 & 07 & 01 & Minas Novas & $\begin{array}{l}\text { Minas } \\
\text { Novas }\end{array}$ & $\begin{array}{l}\text { Itacambira, } \\
\text { Brejo das } \\
\text { Almas, } \\
\text { Cabeceiras } \\
\text { do Rio Verde } \\
\text { e Olhos } \\
\text { d'Água* }\end{array}$ & 03467 & 98,0 & 087 & 68 \\
\hline 14 & 03 & 06 & $\begin{array}{l}\text { Miner. Central } \\
\text { Oeste }\end{array}$ & Caeté & $\begin{array}{l}\text { Santa } \\
\text { Bárbara* }\end{array}$ & 01514 & 71,9 & 053 & 68 \\
\hline 17 & 04 & 07 & Sul Central & Campanha & São Gonçalo* & 03580 & 75,0 & 062 & 68 \\
\hline 14 & 12 & 02 & $\begin{array}{l}\text { Miner. Central } \\
\text { Oeste }\end{array}$ & Sabará & Congonhas* & 00865 & 62,3 & 061 & 68 \\
\hline 02 & 09 & 12 & $\begin{array}{l}\text { Vale Alto } \\
\text { Médio } \\
\text { S. Franc. }\end{array}$ & Paracatu & Januária* & 01970 & 80,8 & 068 & 68 \\
\hline 07 & 12 & 08 & $\begin{array}{l}\text { Médio Baixo } \\
\text { R. Velhas }\end{array}$ & Sabará & Traíras & 03589 & 73,7 & 056 & 66 \\
\hline 14 & 06 & 19 & $\begin{array}{l}\text { Miner. Central } \\
\text { Oeste }\end{array}$ & Mariana & Passagem* & 00918 & 75,5 & 055 & 66 \\
\hline 14 & 08 & 09 & $\begin{array}{l}\text { Miner. Central } \\
\text { Oeste }\end{array}$ & Ouro Preto & $\begin{array}{l}\text { São Bar- } \\
\text { tolomeu* }\end{array}$ & 01211 & 84,9 & 046 & 66 \\
\hline 11 & 16 & 04 & $\begin{array}{l}\text { Inter. Pitan- } \\
\text { gui-Taman. }\end{array}$ & Tamanduá & $\begin{array}{l}\text { Santo Antônio } \\
\text { do Monte* }\end{array}$ & 03150 & 68,1 & 059 & 65 \\
\hline 11 & 14 & 10 & $\begin{array}{l}\text { Inter. Pitan- } \\
\text { gui-Taman. }\end{array}$ & $\begin{array}{l}\text { S. José } \\
\text { Del Rei }\end{array}$ & Lage* $^{*}$ & 01243 & 74,0 & 051 & 65 \\
\hline 14 & 06 & 25 & $\begin{array}{l}\text { Miner. Central } \\
\text { Oeste }\end{array}$ & Mariana & Forquim* & 01516 & 78,4 & 052 & 65 \\
\hline 14 & 08 & 04 & $\begin{array}{l}\text { Miner. Central } \\
\text { Oeste }\end{array}$ & Ouro Preto & $\begin{array}{l}\text { Itabira do } \\
\text { Campo* }\end{array}$ & 01155 & 82,7 & 043 & 64 \\
\hline 14 & 03 & 15 & $\begin{array}{l}\text { Miner. Central } \\
\text { Oeste }\end{array}$ & Caeté & $\begin{array}{l}\text { Conceição do } \\
\text { Rio Acima* }\end{array}$ & 00430 & 77,9 & 031 & 64 \\
\hline 02 & 15 & 06 & $\begin{array}{l}\text { Vale Alto } \\
\text { Médio } \\
\text { S. Franc. }\end{array}$ & $\begin{array}{l}\text { Vila do } \\
\text { Príncipe }\end{array}$ & Extrema & 00901 & 84,5 & 045 & 64 \\
\hline 10 & 09 & 05 & Araxá & Paracatu & Coromandel* & 01952 & 63,5 & 044 & 63 \\
\hline 14 & 03 & 11 & $\begin{array}{l}\text { Miner. Central } \\
\text { Oeste }\end{array}$ & Caeté & $\begin{array}{c}\text { São Gonçalo } \\
\text { do } \\
\text { Rio Acima* }\end{array}$ & 00381 & 76,9 & 031 & 63 \\
\hline
\end{tabular}




\begin{tabular}{|c|c|c|c|c|c|c|c|c|c|}
\hline $\begin{array}{l}\text { Código } \\
\text { Regiẫo }\end{array}$ & $\begin{array}{l}\text { Código } \\
\text { Município }\end{array}$ & $\begin{array}{l}\text { Código } \\
\text { Distrito }\end{array}$ & Região & Município & Distrito & População & $\begin{array}{c}\text { População } \\
\text { com } \\
\text { informação } \\
\text { de ocupação } \\
\text { (\%) }\end{array}$ & $\begin{array}{c}\text { № de } \\
\text { ocupações } \\
\text { com } \\
\text { frequência }\end{array}$ & Pontuação \\
\hline 14 & 11 & 05 & $\begin{array}{l}\text { Miner. Central } \\
\text { Oeste }\end{array}$ & Queluz & Itaverava* & 02014 & 81,5 & 051 & 63 \\
\hline 14 & 12 & 03 & $\begin{array}{l}\text { Miner. Central } \\
\text { Oeste }\end{array}$ & Sabará & $\begin{array}{l}\text { Contagem } \\
\text { das } \\
\text { Abóboras* }\end{array}$ & 02164 & 57,1 & 049 & 63 \\
\hline 14 & 06 & 31 & $\begin{array}{l}\text { Miner. Central } \\
\text { Oeste }\end{array}$ & Mariana & $\begin{array}{l}\text { N. Sra. da } \\
\text { Saúde* }\end{array}$ & 01097 & 52,5 & 047 & 63 \\
\hline 14 & 12 & 06 & $\begin{array}{l}\text { Miner. Central } \\
\text { Oeste }\end{array}$ & Sabará & $\begin{array}{l}\text { N. Sra. da } \\
\text { Lapa }\end{array}$ & 01311 & 65,4 & 034 & 62 \\
\hline 15 & 06 & 27 & Mata & Mariana & $\begin{array}{c}\text { Santana do } \\
\text { Deserto* }\end{array}$ & 01942 & 77,5 & 035 & 62 \\
\hline 14 & 06 & 12 & $\begin{array}{l}\text { Miner. Central } \\
\text { Oeste }\end{array}$ & Mariana & $\begin{array}{c}\text { N. S. das } \\
\text { Neves da Boa } \\
\text { Vista }\end{array}$ & 01005 & 82,2 & 028 & 62 \\
\hline 11 & 14 & 01 & $\begin{array}{l}\text { Inter. Pitan- } \\
\text { gui-Taman. }\end{array}$ & $\begin{array}{l}\text { S. José Del } \\
\text { Rei }\end{array}$ & $\begin{array}{l}\text { Lagoa Dou- } \\
\text { rada* }\end{array}$ & 02169 & 61,4 & 051 & 61 \\
\hline 09 & 09 & 02 & Triângulo & Paracatu & $\begin{array}{l}\text { Dores do } \\
\text { Campo } \\
\text { Formoso* }\end{array}$ & 02317 & 67,8 & 041 & 61 \\
\hline 16 & 01 & 05 & Sudeste & Baependi & $\begin{array}{c}\text { Santa Ana do } \\
\text { Goapeara* }\end{array}$ & 00973 & 70,9 & 042 & 61 \\
\hline 15 & 06 & 11 & Mata & Mariana & $\begin{array}{l}\text { São Manoel } \\
\text { do Pomba* }\end{array}$ & 01305 & 69,3 & 041 & 61 \\
\hline 16 & 02 & 04 & Sudeste & Barbacena & Alberto Dias* & 01025 & 67,5 & 035 & 61 \\
\hline 16 & 01 & 10 & Sudeste & Baependi & Varadouro* & 00629 & 76,2 & 024 & 61 \\
\hline 11 & 14 & 08 & $\begin{array}{l}\text { Inter. Pitan- } \\
\text { gui-Taman. }\end{array}$ & $\begin{array}{c}\text { S. José Del } \\
\text { Rei }\end{array}$ & $\begin{array}{c}\text { Carmo da } \\
\text { Mata* }^{\star}\end{array}$ & 00595 & 73,3 & 024 & 61 \\
\hline 14 & 06 & 22 & $\begin{array}{l}\text { Miner. Central } \\
\text { Oeste }\end{array}$ & Mariana & $\begin{array}{l}\text { São Gonçalo } \\
\text { de Ubá }\end{array}$ & 00912 & 78,0 & 033 & 61 \\
\hline 15 & 02 & 08 & Mata & Barbacena & $\begin{array}{l}\text { São José da } \\
\text { Paraíba* }\end{array}$ & 01356 & 68,7 & 037 & 61 \\
\hline 07 & 12 & 23 & $\begin{array}{l}\text { Médio Baixo } \\
\text { R. Velhas }\end{array}$ & Sabará & Fidalgo* & 01417 & 71,6 & 039 & 61 \\
\hline 14 & 11 & 03 & $\begin{array}{l}\text { Miner. Central } \\
\text { Oeste }\end{array}$ & Queluz & Dores & 01002 & 70,7 & 018 & 61 \\
\hline 14 & 11 & 04 & $\begin{array}{l}\text { Miner. Central } \\
\text { Oeste }\end{array}$ & Queluz & Glória & 01172 & 77,5 & 021 & 61 \\
\hline 14 & 11 & 08 & $\begin{array}{l}\text { Miner. Central } \\
\text { Oeste }\end{array}$ & Queluz & Rio do Peixe & 01362 & 72,5 & 034 & 61 \\
\hline 14 & 12 & 24 & $\begin{array}{l}\text { Miner. Central } \\
\text { Oeste }\end{array}$ & Sabará & $\begin{array}{c}\text { Santa Luzia } \\
\text { do Rio Manso }\end{array}$ & 00957 & 72,9 & 036 & 61 \\
\hline 17 & 13 & 08 & Sul Central & $\begin{array}{l}\text { S. João Del } \\
\text { Rei }\end{array}$ & Rozário* & 00683 & 75,0 & 016 & 61 \\
\hline 11 & 14 & 16 & $\begin{array}{l}\text { Inter. Pitan- } \\
\text { gui-Taman. }\end{array}$ & $\begin{array}{l}\text { S. José Del } \\
\text { Rei }\end{array}$ & $\begin{array}{c}\text { Bom } \\
\text { Sucesso* }\end{array}$ & 03070 & 76,6 & 033 & 60 \\
\hline 16 & 02 & 05 & Sudeste & Barbacena & $\begin{array}{c}\text { Santa Ana do } \\
\text { Barroso* }\end{array}$ & 00617 & 66,6 & 023 & 60 \\
\hline 14 & 11 & 13 & $\begin{array}{l}\text { Miner. Central } \\
\text { Oeste }\end{array}$ & Queluz & Santo Amaro & 01013 & 72,4 & 036 & 60 \\
\hline 14 & 15 & 08 & $\begin{array}{l}\text { Miner. Central } \\
\text { Oeste }\end{array}$ & $\begin{array}{l}\text { Vila do } \\
\text { Príncipe }\end{array}$ & Paraúnas & 00914 & 81,6 & 031 & 60 \\
\hline 14 & 08 & 11 & $\begin{array}{l}\text { Miner. Central } \\
\text { Oeste }\end{array}$ & Ouro Preto & $\begin{array}{l}\text { São Jose da } \\
\text { Paraopeba }\end{array}$ & 00676 & 75,6 & 032 & 60 \\
\hline
\end{tabular}




\begin{tabular}{|c|c|c|c|c|c|c|c|c|c|}
\hline $\begin{array}{l}\text { Código } \\
\text { Regiẫo }\end{array}$ & $\begin{array}{l}\text { Código } \\
\text { Município }\end{array}$ & $\begin{array}{l}\text { Código } \\
\text { Distrito }\end{array}$ & Região & Município & Distrito & População & $\begin{array}{c}\text { População } \\
\text { com } \\
\text { informação } \\
\text { de ocupação } \\
(\%)\end{array}$ & $\begin{array}{l}\text { № de } \\
\text { ocupações } \\
\text { com } \\
\text { frequência }\end{array}$ & Pontuação \\
\hline 10 & 09 & 07 & Araxá & Paracatu & $\begin{array}{l}\text { São Fran- } \\
\text { cisco das } \\
\text { Chagas* }\end{array}$ & 02069 & 61,8 & 019 & 60 \\
\hline 14 & 08 & 13 & $\begin{array}{l}\text { Miner. Central } \\
\text { Oeste }\end{array}$ & Ouro Preto & $\begin{array}{l}\text { São Gonçalo } \\
\text { do Tejuco }\end{array}$ & 00876 & 73,5 & 025 & 60 \\
\hline 11 & 14 & 21 & $\begin{array}{l}\text { Inter. Pitan- } \\
\text { gui-Taman. }\end{array}$ & $\begin{array}{l}\text { S. José Del } \\
\text { Rei }\end{array}$ & $\begin{array}{l}\text { São João } \\
\text { Batista* }\end{array}$ & 00784 & 69,1 & 015 & 59 \\
\hline 16 & 13 & 13 & Sudeste & $\begin{array}{l}\text { S. João Del } \\
\text { Rei }\end{array}$ & $\begin{array}{l}\text { São Miguel } \\
\text { do Cajuru* }\end{array}$ & 00944 & 71,3 & 025 & 59 \\
\hline 14 & 06 & 01 & $\begin{array}{l}\text { Miner. Central } \\
\text { Oeste }\end{array}$ & Mariana & $\begin{array}{c}\text { Conceição do } \\
\text { Turvo }\end{array}$ & 00995 & 75,2 & 028 & 59 \\
\hline 14 & 06 & 34 & $\begin{array}{l}\text { Miner. Central } \\
\text { Oeste }\end{array}$ & Mariana & Remédios & 01337 & 76,8 & 028 & 59 \\
\hline 14 & 08 & 03 & $\begin{array}{l}\text { Miner. Central } \\
\text { Oeste }\end{array}$ & Ouro Preto & $\begin{array}{l}\text { N. Sra. da } \\
\text { Boa Morte }\end{array}$ & 01132 & 73,7 & 020 & 59 \\
\hline 14 & 08 & 02 & $\begin{array}{l}\text { Miner. Central } \\
\text { Oeste }\end{array}$ & Ouro Preto & $\begin{array}{l}\text { Congonhas } \\
\text { do Campo }\end{array}$ & 01333 & 73,7 & 043 & 59 \\
\hline 14 & 08 & 12 & $\begin{array}{l}\text { Miner. Central } \\
\text { Oeste }\end{array}$ & Ouro Preto & $\begin{array}{l}\text { São Gonçalo } \\
\text { do Bação }\end{array}$ & 00578 & 78,9 & 027 & 59 \\
\hline 18 & 05 & 02 & Sudoeste & Jacuí & Machado & 00923 & 65,2 & 020 & 59 \\
\hline 18 & 05 & 09 & Sudoeste & Jacuí & $\begin{array}{l}\text { São Francis- } \\
\text { co de Paula } \\
\text { do Tejuco* }\end{array}$ & 01327 & 60,0 & 011 & 59 \\
\hline 14 & 08 & 14 & $\begin{array}{l}\text { Miner. Central } \\
\text { Oeste }\end{array}$ & Ouro Preto & $\begin{array}{l}\text { N. Sra. da } \\
\text { Soledade }\end{array}$ & 00412 & 76,7 & 030 & 59 \\
\hline 15 & 06 & 05 & Mata & Mariana & $\begin{array}{l}\text { Sta. Rita da } \\
\text { Meia Pataca* }\end{array}$ & 00753 & 61,6 & 023 & 59 \\
\hline 14 & 03 & 10 & $\begin{array}{l}\text { Miner. Central } \\
\text { Oeste }\end{array}$ & Caeté & Brumado & 01012 & 60,3 & 039 & 59 \\
\hline 11 & 14 & 02 & $\begin{array}{l}\text { Inter. Pitan- } \\
\text { gui-Taman. }\end{array}$ & $\begin{array}{c}\text { S. José Del } \\
\text { Rei }\end{array}$ & $\begin{array}{l}\text { Santa Rita do } \\
\text { Rio Abaixo }\end{array}$ & 01327 & 74,2 & 022 & 58 \\
\hline 11 & 16 & 06 & $\begin{array}{l}\text { Inter. Pitan- } \\
\text { gui-Taman. }\end{array}$ & Tamanduá & Desterro* & 02221 & 62,9 & 026 & 58 \\
\hline 10 & 09 & 01 & Araxá & Paracatu & Carmo & 00560 & 75,5 & 018 & 58 \\
\hline 14 & 12 & 09 & $\begin{array}{l}\text { Miner. Central } \\
\text { Oeste }\end{array}$ & Sabará & Santa Rita & 00410 & 70,5 & 026 & 58 \\
\hline 14 & 12 & 26 & $\begin{array}{l}\text { Miner. Central } \\
\text { Oeste }\end{array}$ & Sabará & $\begin{array}{l}\text { São Se- } \\
\text { bastião do } \\
\text { Itatiaia }\end{array}$ & 01103 & 60,2 & 026 & 58 \\
\hline 14 & 11 & 16 & $\begin{array}{l}\text { Miner. Central } \\
\text { Oeste }\end{array}$ & Queluz & $\begin{array}{l}\text { São Gonçalo } \\
\text { da Ponte }\end{array}$ & 00530 & 61,3 & 010 & 58 \\
\hline 15 & 02 & 02 & Mata & Barbacena & $\begin{array}{l}\text { Espírito } \\
\text { Santo* }\end{array}$ & 01292 & 63,2 & 021 & 57 \\
\hline 14 & 06 & 32 & $\begin{array}{l}\text { Miner. Central } \\
\text { Oeste }\end{array}$ & Mariana & Barra Longa & 00263 & 73,4 & 012 & 57 \\
\hline 11 & 16 & 05 & $\begin{array}{l}\text { Inter. Pitan- } \\
\text { gui-Taman. }\end{array}$ & Tamanduá & Formiga & 06026 & 56,6 & 039 & 56 \\
\hline 13 & 15 & 14 & $\begin{array}{l}\text { Miner. Central } \\
\text { Leste }\end{array}$ & $\begin{array}{l}\text { Vila do } \\
\text { Príncipe }\end{array}$ & $\begin{array}{c}\text { Nossa } \\
\text { Senhora do } \\
\text { Porto* }\end{array}$ & 02854 & 59,7 & 019 & 56 \\
\hline 07 & 12 & 04 & $\begin{array}{l}\text { Médio Baixo } \\
\text { R. Velhas }\end{array}$ & Sabará & Matosinhos & 02705 & 47,3 & 052 & 56 \\
\hline 07 & 12 & 22 & $\begin{array}{c}\text { Médio Baixo } \\
\text { R. Velhas }\end{array}$ & Sabará & Pilar & 00670 & 59,3 & 037 & 55 \\
\hline
\end{tabular}




\begin{tabular}{|c|c|c|c|c|c|c|c|c|c|}
\hline $\begin{array}{l}\text { Código } \\
\text { Região }\end{array}$ & $\begin{array}{l}\text { Código } \\
\text { Município }\end{array}$ & $\begin{array}{l}\text { Código } \\
\text { Distrito }\end{array}$ & Região & Município & Distrito & População & $\begin{array}{c}\text { População } \\
\text { com } \\
\text { informação } \\
\text { de ocupação } \\
(\%)\end{array}$ & $\begin{array}{l}\text { № de } \\
\text { ocupações } \\
\text { com } \\
\text { frequência }\end{array}$ & Pontuação \\
\hline 14 & 11 & 17 & $\begin{array}{l}\text { Miner. Central } \\
\text { Oeste }\end{array}$ & Queluz & $\begin{array}{l}\text { Senhor do } \\
\text { Bonfim }\end{array}$ & 01726 & 57,2 & 038 & 54 \\
\hline 14 & 06 & 20 & $\begin{array}{l}\text { Miner. Central } \\
\text { Oeste }\end{array}$ & Mariana & Guarapiranga & 02006 & 52,7 & 054 & 54 \\
\hline 16 & 13 & 16 & Sudeste & $\begin{array}{l}\text { S. João Del } \\
\text { Rei }\end{array}$ & $\begin{array}{l}\text { Madre de } \\
\text { Deus* }\end{array}$ & 00345 & 52,2 & 026 & 52 \\
\hline 10 & 09 & 04 & Araxá & Paracatu & $\begin{array}{c}\text { Santana da } \\
\text { Barra do Rio } \\
\text { do Espírito }\end{array}$ & 02444 & 48,8 & 042 & 52 \\
\hline 06 & 10 & 03 & $\begin{array}{l}\text { Sertão Alto S. } \\
\text { Franc. }\end{array}$ & Pitangui & $\begin{array}{c}\text { Senhora das } \\
\text { Dores* }\end{array}$ & 02025 & 50,2 & 015 & 51 \\
\hline 14 & 12 & 18 & $\begin{array}{l}\text { Miner. Central } \\
\text { Oeste }\end{array}$ & Sabará & $\begin{array}{l}\text { Piedade do } \\
\text { Paraopeba }\end{array}$ & 01091 & 58,4 & 030 & 51 \\
\hline 14 & 11 & 14 & $\begin{array}{l}\text { Miner. Central } \\
\text { Oeste }\end{array}$ & Queluz & Redondo & 01077 & 60,9 & 033 & 50 \\
\hline 16 & 13 & 09 & Sudeste & $\begin{array}{l}\text { S. João Del } \\
\text { Rei }\end{array}$ & $\begin{array}{l}\text { Santana do } \\
\text { Garumbeo* }\end{array}$ & 00720 & 55,1 & 014 & 49 \\
\hline 14 & 06 & 36 & $\begin{array}{l}\text { Miner. Central } \\
\text { Oeste }\end{array}$ & Mariana & São Caetano & 00989 & 53,0 & 050 & 48 \\
\hline 14 & 06 & 02 & $\begin{array}{l}\text { Miner. Central } \\
\text { Oeste }\end{array}$ & Mariana & Mariana & 02972 & 49,2 & 093 & 48 \\
\hline 11 & 12 & 15 & $\begin{array}{l}\text { Inter. Pitan- } \\
\text { gui-Taman. }\end{array}$ & Sabará & $\begin{array}{l}\text { Piedade do } \\
\text { Bagre }\end{array}$ & 01896 & 47,6 & 031 & 47 \\
\hline 13 & 03 & 01 & $\begin{array}{l}\text { Miner. Central } \\
\text { Leste }\end{array}$ & Caeté & Antônio Dias* & 01630 & 46,6 & 021 & 46 \\
\hline 14 & 06 & 14 & $\begin{array}{l}\text { Miner. Central } \\
\text { Oeste }\end{array}$ & Mariana & $\begin{array}{l}\text { Santo Antônio } \\
\text { do Calambao }\end{array}$ & 01407 & 45,5 & 044 & 46 \\
\hline 14 & 12 & 21 & $\begin{array}{l}\text { Miner. Central } \\
\text { Oeste }\end{array}$ & Sabará & $\begin{array}{l}\text { Jesus, Maria } \\
\text { e José do } \\
\text { Aranha }\end{array}$ & 00771 & 45,5 & 029 & 46 \\
\hline 14 & 15 & 13 & $\begin{array}{l}\text { Miner. Central } \\
\text { Oeste }\end{array}$ & $\begin{array}{l}\text { Vila do } \\
\text { Príncipe }\end{array}$ & Córregos & 01113 & 47,5 & 037 & 45 \\
\hline 05 & 09 & 11 & Paracatu & Paracatu & Buritis* & 01740 & 43,4 & 028 & 44 \\
\hline 11 & 14 & 06 & $\begin{array}{l}\text { Inter. Pitan- } \\
\text { gui-Taman. }\end{array}$ & $\begin{array}{c}\text { S. José Del } \\
\text { Rei }\end{array}$ & Olhos d'Água & 00565 & 46,4 & 019 & 43 \\
\hline 14 & 03 & 04 & $\begin{array}{l}\text { Miner. Central } \\
\text { Oeste }\end{array}$ & Caeté & $\begin{array}{l}\text { Nossa } \\
\text { Senhora do } \\
\text { Socorro }\end{array}$ & 01133 & 45,0 & 042 & 40 \\
\hline 18 & 05 & 05 & Sudoeste & Jacuí & $\begin{array}{l}\text { São Joaquim } \\
\text { do Senhor }\end{array}$ & 01763 & 48,8 & 033 & 39 \\
\hline 16 & 01 & 04 & Sudeste & Baependi & $\begin{array}{l}\text { N. Sra. do } \\
\text { Carmo do } \\
\text { Pouso Alto* }\end{array}$ & 03402 & 39,2 & 038 & 33 \\
\hline 17 & 04 & 03 & Sul Central & Campanha & Lambari* & 02077 & 39,9 & 025 & 33 \\
\hline 08 & 06 & 16 & $\begin{array}{l}\text { Sertão do Rio } \\
\text { Doce }\end{array}$ & Mariana & Cuieté* & 00267 & 46,8 & 020 & 32 \\
\hline 14 & 03 & 08 & $\begin{array}{l}\text { Miner. Central } \\
\text { Oeste }\end{array}$ & Caeté & $\begin{array}{l}\text { São Gonçalo } \\
\text { do Rio Abaixo }\end{array}$ & 02834 & 39,8 & 096 & 32 \\
\hline 12 & 15 & 15 & Diamantina & $\begin{array}{l}\text { Vila do } \\
\text { Príncipe }\end{array}$ & Corimataí* & 02812 & 43,9 & 036 & 31 \\
\hline 14 & 12 & 14 & $\begin{array}{l}\text { Miner. Central } \\
\text { Oeste }\end{array}$ & Sabará & $\begin{array}{l}\text { São Se- } \\
\text { bastião de } \\
\text { Macacos }\end{array}$ & 00190 & 47,4 & 018 & 31 \\
\hline
\end{tabular}




\begin{tabular}{|c|c|c|c|c|c|c|c|c|c|}
\hline $\begin{array}{l}\text { Código } \\
\text { Região }\end{array}$ & $\begin{array}{l}\text { Código } \\
\text { Município }\end{array}$ & $\begin{array}{l}\text { Código } \\
\text { Distrito }\end{array}$ & Região & Município & Distrito & População & $\begin{array}{c}\text { População } \\
\text { com } \\
\text { informação } \\
\text { de ocupação } \\
\text { (\%) }\end{array}$ & $\begin{array}{l}\text { № de } \\
\text { ocupações } \\
\text { com } \\
\text { frequência }\end{array}$ & Pontuação \\
\hline 14 & 11 & 07 & $\begin{array}{l}\text { Miner. Central } \\
\text { Oeste }\end{array}$ & Queluz & $\begin{array}{l}\text { Vila de } \\
\text { Queluz }\end{array}$ & 01633 & 39,7 & 049 & 31 \\
\hline 03 & 12 & 13 & Sertão & Sabará & $\begin{array}{c}\text { Santíssimo } \\
\text { Coração de } \\
\text { Jesus* }\end{array}$ & 02690 & 36,8 & 055 & 30 \\
\hline 17 & 04 & 01 & Sul Central & Campanha & Mutuca* & 02169 & 36,1 & 028 & 29 \\
\hline 10 & 09 & 08 & Araxá & Paracatu & $\begin{array}{l}\text { São Pedro de } \\
\text { Alcântara }\end{array}$ & 01463 & 40,5 & 031 & 29 \\
\hline 11 & 10 & 02 & $\begin{array}{l}\text { Inter. Pitan- } \\
\text { gui-Taman. }\end{array}$ & Pitangui & $\begin{array}{l}\text { São Gonçalo } \\
\text { do Pará }\end{array}$ & 01500 & 40,9 & 035 & 29 \\
\hline 14 & 08 & 06 & $\begin{array}{l}\text { Miner. Central } \\
\text { Oeste }\end{array}$ & Ouro Preto & Santa Rita & 00349 & 41,3 & 021 & 29 \\
\hline 12 & 15 & 10 & Diamantina & $\begin{array}{l}\text { Vila do } \\
\text { Príncipe }\end{array}$ & Gouveia* & 02024 & 35,7 & 107 & 28 \\
\hline 11 & 16 & 01 & $\begin{array}{l}\text { Inter. Pitan- } \\
\text { gui-Taman. }\end{array}$ & Tamanduá & $\begin{array}{l}\text { Bom Jesus } \\
\text { da Pedra } \\
\text { do Indaiá }\end{array}$ & 01089 & 37,2 & 025 & 28 \\
\hline 16 & 13 & 11 & Sudeste & $\begin{array}{l}\text { S. João Del } \\
\text { Rei }\end{array}$ & $\begin{array}{l}\text { São Gonçalo } \\
\text { do Brumado* }\end{array}$ & 00357 & 41,7 & 018 & 27 \\
\hline 11 & 14 & 18 & $\begin{array}{l}\text { Inter. Pitan- } \\
\text { gui-Taman. }\end{array}$ & $\begin{array}{c}\text { S. José Del } \\
\text { Rei }\end{array}$ & Padre Gaspar & 00718 & 40,7 & 032 & 27 \\
\hline 14 & 06 & 18 & $\begin{array}{l}\text { Miner. Central } \\
\text { Oeste }\end{array}$ & Mariana & $\begin{array}{l}\text { São José do } \\
\text { Crato }\end{array}$ & 00369 & 36,6 & 019 & 27 \\
\hline 17 & 13 & 05 & Sul Central & $\begin{array}{l}\text { S. João Del } \\
\text { Rei }\end{array}$ & $\begin{array}{l}\text { Dores da Boa } \\
\text { Esperança }\end{array}$ & 04060 & 35,6 & 041 & 25 \\
\hline 11 & 14 & 17 & $\begin{array}{l}\text { Inter. Pitan- } \\
\text { gui-Taman. }\end{array}$ & $\begin{array}{l}\text { S. José Del } \\
\text { Rei }\end{array}$ & $\begin{array}{l}\text { Santo Antonio } \\
\text { do Amparo }\end{array}$ & 01924 & 40,3 & 042 & 24 \\
\hline 11 & 14 & 15 & $\begin{array}{l}\text { Inter. Pitan- } \\
\text { gui-Taman. }\end{array}$ & $\begin{array}{c}\text { S. José Del } \\
\text { Rei }\end{array}$ & Desterro & 00540 & 39,1 & 015 & 24 \\
\hline 14 & 11 & 02 & $\begin{array}{l}\text { Miner. Central } \\
\text { Oeste }\end{array}$ & Queluz & $\begin{array}{l}\text { Catas Altas } \\
\text { de Itaverava }\end{array}$ & 01616 & 37,1 & 053 & 24 \\
\hline 11 & 14 & 09 & $\begin{array}{l}\text { Inter. Pitan- } \\
\text { gui-Taman. }\end{array}$ & $\begin{array}{c}\text { S. José Del } \\
\text { Rei }\end{array}$ & Cana Verde & 01160 & 39,1 & 025 & 23 \\
\hline 04 & 07 & 04 & Minas Novas & $\begin{array}{l}\text { Minas } \\
\text { Novas }\end{array}$ & Minas Novas* & 04146 & 36,7 & 053 & 23 \\
\hline 16 & 01 & 07 & Sudeste & Baependi & São Vicente* & 01367 & 32,6 & 038 & 21 \\
\hline 17 & 13 & 04 & Sul Central & $\begin{array}{l}\text { S. João Del } \\
\text { Rei }\end{array}$ & $\begin{array}{l}\text { Espírito Santo } \\
\text { da Varginha }\end{array}$ & 01857 & 34,0 & 037 & 19 \\
\hline 14 & 03 & 09 & $\begin{array}{l}\text { Miner. Central } \\
\text { Oeste }\end{array}$ & Caeté & $\begin{array}{l}\text { Penha de } \\
\text { França }\end{array}$ & 01021 & 36,3 & 050 & 19 \\
\hline 12 & 15 & 17 & Diamantina & $\begin{array}{l}\text { Vila do } \\
\text { Príncipe }\end{array}$ & $\begin{array}{l}\text { Vila do } \\
\text { Príncipe }\end{array}$ & 04467 & 35,1 & 066 & 18 \\
\hline 18 & 05 & 03 & Sudoeste & Jacuí & $\begin{array}{l}\text { Santa Rita do } \\
\text { Rio Claro }\end{array}$ & 01016 & 32,3 & 016 & 18 \\
\hline 06 & 16 & 03 & $\begin{array}{l}\text { Sertão Alto S. } \\
\text { Franc. }\end{array}$ & Tamanduá & Bambuí & 03540 & 31,4 & 109 & 17 \\
\hline 14 & 12 & 11 & $\begin{array}{l}\text { Miner. Central } \\
\text { Oeste }\end{array}$ & Sabará & $\begin{array}{c}\text { S. A. da } \\
\text { Mouraria do } \\
\text { Arraial Velho }\end{array}$ & 00620 & 29,7 & 037 & 17 \\
\hline 13 & 06 & 08 & $\begin{array}{l}\text { Miner. Central } \\
\text { Leste }\end{array}$ & Mariana & $\begin{array}{l}\text { São Domin- } \\
\text { gos }\end{array}$ & 01308 & 35,7 & 042 & 15 \\
\hline 07 & 12 & 17 & $\begin{array}{l}\text { Médio Baixo } \\
\text { R. Velhas }\end{array}$ & Sabará & $\begin{array}{l}\text { Taquarassu } \\
\text { de Cima }\end{array}$ & 02087 & 34,6 & 040 & 14 \\
\hline
\end{tabular}




\begin{tabular}{|c|c|c|c|c|c|c|c|c|c|}
\hline $\begin{array}{l}\text { Código } \\
\text { Regiẫo }\end{array}$ & $\begin{array}{l}\text { Código } \\
\text { Município }\end{array}$ & $\begin{array}{l}\text { Código } \\
\text { Distrito }\end{array}$ & Região & Município & Distrito & População & $\begin{array}{c}\text { População } \\
\text { com } \\
\text { informação } \\
\text { de ocupação } \\
(\%)\end{array}$ & $\begin{array}{l}\text { № de } \\
\text { ocupaçõos } \\
\text { com } \\
\text { frequência }\end{array}$ & Pontuação \\
\hline 07 & 12 & 07 & $\begin{array}{l}\text { Médio Baixo } \\
\text { R. Velhas }\end{array}$ & Sabará & Alagoa Santa & 01825 & 35,2 & 028 & 14 \\
\hline 11 & 10 & 04 & $\begin{array}{l}\text { Inter. Pitan- } \\
\text { gui-Taman. }\end{array}$ & Pitangui & $\begin{array}{l}\text { Santana do } \\
\text { Rio de São } \\
\text { João Acima }\end{array}$ & 02758 & 33,4 & 048 & 13 \\
\hline 17 & 04 & 04 & Sul Central & Campanha & $\begin{array}{c}\text { Santa Cata- } \\
\text { rina }\end{array}$ & 02542 & 29,9 & 026 & 13 \\
\hline 12 & 15 & 09 & Diamantina & $\begin{array}{l}\text { Vila do } \\
\text { Príncipe }\end{array}$ & $\begin{array}{l}\text { São Gonçalo } \\
\text { e Milho Verde }\end{array}$ & 01437 & 27,5 & 052 & 12 \\
\hline 16 & 02 & 01 & Sudeste & Barbacena & Barbacena & 02744 & 26,6 & 064 & 12 \\
\hline 11 & 14 & 11 & $\begin{array}{l}\text { Inter. Pitan- } \\
\text { gui-Taman. }\end{array}$ & $\begin{array}{l}\text { S. José Del } \\
\text { Rei }\end{array}$ & Prados & 02532 & 23,9 & 048 & 12 \\
\hline 14 & 03 & 02 & $\begin{array}{l}\text { Miner. Central } \\
\text { Oeste }\end{array}$ & Caeté & Cocaes & 03004 & 20,8 & 051 & 12 \\
\hline 14 & 11 & 18 & $\begin{array}{l}\text { Miner. Central } \\
\text { Oeste }\end{array}$ & Queluz & $\begin{array}{c}\text { N. S. da } \\
\text { Conceição da } \\
\text { Noruega }\end{array}$ & 00994 & 29,0 & 045 & 11 \\
\hline 16 & 01 & 09 & Sudeste & Baependi & Turvo & 04628 & 22,8 & 056 & 10 \\
\hline 11 & 14 & 20 & $\begin{array}{l}\text { Inter. Pitan- } \\
\text { gui-Taman. }\end{array}$ & $\begin{array}{l}\text { S. José Del } \\
\text { Rei }\end{array}$ & São Tiago & 01154 & 32,1 & 029 & 10 \\
\hline 18 & 05 & 10 & Sudoeste & Jacuí & $\begin{array}{l}\text { Santa Maria } \\
\text { Madalena do } \\
\text { Aterrado }\end{array}$ & 01124 & 27,3 & 019 & 10 \\
\hline 14 & 08 & 15 & $\begin{array}{l}\text { Miner. Central } \\
\text { Oeste }\end{array}$ & Ouro Preto & Ouro Preto & 03695 & 18,8 & 057 & 10 \\
\hline 11 & 16 & 02 & $\begin{array}{l}\text { Inter. Pitan- } \\
\text { gui-Taman. }\end{array}$ & Tamanduá & Candeias & 01275 & 26,9 & 021 & 10 \\
\hline 14 & 15 & 07 & $\begin{array}{l}\text { Miner. Central } \\
\text { Oeste }\end{array}$ & $\begin{array}{l}\text { Vila do } \\
\text { Príncipe }\end{array}$ & $\begin{array}{l}\text { Santo Antônio } \\
\text { da Tapera }\end{array}$ & 00741 & 29,1 & 037 & 10 \\
\hline 14 & 12 & 01 & $\begin{array}{l}\text { Miner. Central } \\
\text { Oeste }\end{array}$ & Sabará & Betim & 02327 & 32,5 & 052 & 10 \\
\hline 14 & 06 & 13 & $\begin{array}{l}\text { Miner. Central } \\
\text { Oeste }\end{array}$ & Mariana & $\begin{array}{c}\text { Bento } \\
\text { Rodrigues }\end{array}$ & 00454 & 32,4 & 023 & 10 \\
\hline 17 & 13 & 12 & Sul Central & $\begin{array}{c}\text { S. João Del } \\
\text { Rei }\end{array}$ & $\begin{array}{c}\text { São João } \\
\text { Neponuceno }\end{array}$ & 02607 & 29,1 & 031 & 09 \\
\hline 15 & 06 & 15 & Mata & Mariana & $\begin{array}{l}\text { Mercês do } \\
\text { Pomba }\end{array}$ & 01860 & 30,2 & 032 & 09 \\
\hline 14 & 11 & 01 & $\begin{array}{l}\text { Miner. Central } \\
\text { Oeste }\end{array}$ & Queluz & Brumado & 02350 & 30,8 & 031 & 09 \\
\hline 14 & 11 & 09 & $\begin{array}{l}\text { Miner. Central } \\
\text { Oeste }\end{array}$ & Queluz & Santa Ana & 00966 & 24,7 & 043 & 09 \\
\hline 16 & 13 & 06 & Sudeste & $\begin{array}{l}\text { S. João Del } \\
\text { Rei }\end{array}$ & $\begin{array}{l}\text { N. Sra. de } \\
\text { Nazareth }\end{array}$ & 01508 & 18,6 & 040 & 08 \\
\hline 10 & 09 & 06 & Araxá & Paracatu & Araxá & 02811 & 18,8 & 048 & 08 \\
\hline 17 & 04 & 08 & Sul Central & Campanha & $\begin{array}{c}\text { São José do } \\
\text { Campo da } \\
\text { Formiga }\end{array}$ & 02021 & 24,1 & 046 & 08 \\
\hline 04 & 07 & 03 & Minas Novas & $\begin{array}{l}\text { Minas } \\
\text { Novas }\end{array}$ & Grão Mogol & 02269 & 28,5 & 024 & 08 \\
\hline 17 & 04 & 13 & Sul Central & Campanha & $\begin{array}{l}\text { Santana do } \\
\text { Sapucaí }\end{array}$ & 04639 & 16,9 & 045 & 08 \\
\hline 14 & 06 & 28 & $\begin{array}{l}\text { Miner. Central } \\
\text { Oeste }\end{array}$ & Mariana & $\begin{array}{l}\text { São Se- } \\
\text { bastião }\end{array}$ & 00602 & 31,7 & 030 & 08 \\
\hline
\end{tabular}




\begin{tabular}{|c|c|c|c|c|c|c|c|c|c|}
\hline $\begin{array}{l}\text { Código } \\
\text { Regiấo }\end{array}$ & $\begin{array}{l}\text { Código } \\
\text { Município }\end{array}$ & $\begin{array}{l}\text { Código } \\
\text { Distrito }\end{array}$ & Região & Município & Distrito & População & $\begin{array}{c}\text { População } \\
\text { com } \\
\text { informação } \\
\text { de ocupação } \\
(\%)\end{array}$ & $\begin{array}{c}\text { № de } \\
\text { ocupações } \\
\text { com } \\
\text { frequência }\end{array}$ & Pontuação \\
\hline 14 & 11 & 15 & $\begin{array}{l}\text { Miner. Central } \\
\text { Oeste }\end{array}$ & Queluz & Lamin & 01723 & 16,5 & 025 & 08 \\
\hline 14 & 06 & 21 & $\begin{array}{l}\text { Miner. Central } \\
\text { Oeste }\end{array}$ & Mariana & Monja Legoas & 00360 & 35,3 & 013 & 08 \\
\hline 14 & 11 & 10 & $\begin{array}{l}\text { Miner. Central } \\
\text { Oeste }\end{array}$ & Queluz & $\begin{array}{l}\text { Morro do } \\
\text { Chapéu }\end{array}$ & 01026 & 26,6 & 024 & 08 \\
\hline 12 & 15 & 11 & Diamantina & $\begin{array}{l}\text { Vila do } \\
\text { Príncipe }\end{array}$ & Andrequicé & 00807 & 31,7 & 015 & 07 \\
\hline 16 & 13 & 14 & Sudeste & $\begin{array}{l}\text { S. João Del } \\
\text { Rei }\end{array}$ & $\begin{array}{l}\text { Conceição do } \\
\text { Porto }\end{array}$ & 00694 & 16,7 & 023 & 07 \\
\hline 03 & 15 & 02 & Sertão & $\begin{array}{l}\text { Vila do } \\
\text { Príncipe }\end{array}$ & $\begin{array}{l}\text { Vila de For- } \\
\text { migas }\end{array}$ & 03350 & 21,3 & 044 & 07 \\
\hline 11 & 14 & 14 & $\begin{array}{l}\text { Inter. Pitan- } \\
\text { gui-Taman. }\end{array}$ & $\begin{array}{c}\text { S. José Del } \\
\text { Rei }\end{array}$ & $\begin{array}{l}\text { Vila de São } \\
\text { José }\end{array}$ & 03057 & 18,4 & 055 & 07 \\
\hline 14 & 06 & 23 & $\begin{array}{l}\text { Miner. Central } \\
\text { Oeste }\end{array}$ & Mariana & $\begin{array}{c}\text { Conceição da } \\
\text { Várzea }\end{array}$ & 00494 & 26,5 & 015 & 07 \\
\hline 16 & 13 & 17 & Sudeste & $\begin{array}{l}\text { S. João Del } \\
\text { Rei }\end{array}$ & $\begin{array}{l}\text { São João Del } \\
\text { Rei }\end{array}$ & 04033 & 24,0 & 048 & 06 \\
\hline 17 & 04 & 09 & Sul Central & Campanha & $\begin{array}{c}\text { São Se- } \\
\text { bastião da } \\
\text { Capituba }\end{array}$ & 01455 & 25,9 & 042 & 06 \\
\hline 17 & 04 & 12 & Sul Central & Campanha & $\begin{array}{c}\text { Três } \\
\text { Corações }\end{array}$ & 01842 & 16,9 & 043 & 06 \\
\hline 12 & 15 & 04 & Diamantina & $\begin{array}{l}\text { Vila do } \\
\text { Príncipe }\end{array}$ & $\begin{array}{l}\text { Santo Antônio } \\
\text { do Tejuco }\end{array}$ & 12455 & 15,9 & 052 & 06 \\
\hline 10 & 09 & 03 & Araxá & Paracatu & Patrocínio & 01651 & 14,5 & 025 & 06 \\
\hline 17 & 04 & 02 & Sul Central & Campanha & Itajubá & 05217 & 17,2 & 047 & 06 \\
\hline 11 & 14 & 05 & $\begin{array}{l}\text { Inter. Pitan- } \\
\text { gui-Taman. }\end{array}$ & $\begin{array}{l}\text { S. José Del } \\
\text { Rei }\end{array}$ & Ressaca & 00680 & 18,8 & 020 & 06 \\
\hline 14 & 08 & 08 & $\begin{array}{l}\text { Miner. Central } \\
\text { Oeste }\end{array}$ & Ouro Preto & Itatiaia & 00596 & 27,3 & 035 & 06 \\
\hline 17 & 13 & 03 & Sul Central & $\begin{array}{c}\text { S. João Del } \\
\text { Rei }\end{array}$ & $\begin{array}{l}\text { Espírito } \\
\text { Santo dos } \\
\text { Coqueiros }\end{array}$ & 01488 & 24,5 & 019 & 06 \\
\hline 14 & 08 & 05 & $\begin{array}{l}\text { Miner. Central } \\
\text { Oeste }\end{array}$ & Ouro Preto & $\begin{array}{l}\text { Santa Quitéria } \\
\text { da Boa Vista }\end{array}$ & 00964 & 20,4 & 023 & 06 \\
\hline 15 & 02 & 10 & Mata & Barbacena & $\begin{array}{l}\text { Mercês do } \\
\text { Kágado }\end{array}$ & 01186 & 15,1 & 031 & 06 \\
\hline 17 & 04 & 05 & Sul Central & Campanha & Santa Rita & 01808 & 15,3 & 012 & 06 \\
\hline 16 & 13 & 15 & Sudeste & $\begin{array}{l}\text { S. João Del } \\
\text { Rei }\end{array}$ & Bom Jardim & 01105 & 25,0 & 012 & 05 \\
\hline 11 & 14 & 12 & $\begin{array}{l}\text { Inter. Pitan- } \\
\text { gui-Taman. }\end{array}$ & $\begin{array}{c}\text { S. José Del } \\
\text { Rei }\end{array}$ & Perdões & 02051 & 25,5 & 029 & 05 \\
\hline 16 & 01 & 06 & Sudeste & Baependi & $\begin{array}{l}\text { São José do } \\
\text { Favacho }\end{array}$ & 01036 & 15,5 & 022 & 05 \\
\hline 14 & 06 & 35 & $\begin{array}{l}\text { Miner. Central } \\
\text { Oeste }\end{array}$ & Mariana & Camargos & 00352 & 20,7 & 023 & 05 \\
\hline 14 & 08 & 10 & $\begin{array}{l}\text { Miner. Central } \\
\text { Oeste }\end{array}$ & Ouro Preto & Moeda & 00829 & 14,7 & 018 & 05 \\
\hline 14 & 12 & 05 & $\begin{array}{l}\text { Miner. Central } \\
\text { Oeste }\end{array}$ & Sabará & $\begin{array}{l}\text { Rio das } \\
\text { Pedras }\end{array}$ & 00957 & 27,9 & 023 & 05 \\
\hline 11 & 10 & 01 & $\begin{array}{l}\text { Inter. Pitan- } \\
\text { gui-Taman. }\end{array}$ & Pitangui & Abadia & 01828 & 25,3 & 047 & 04 \\
\hline
\end{tabular}




\begin{tabular}{|c|c|c|c|c|c|c|c|c|c|}
\hline $\begin{array}{l}\text { Código } \\
\text { Região }\end{array}$ & $\begin{array}{l}\text { Código } \\
\text { Município }\end{array}$ & $\begin{array}{l}\text { Código } \\
\text { Distrito }\end{array}$ & Região & Município & Distrito & População & $\begin{array}{l}\text { População } \\
\text { com } \\
\text { informação } \\
\text { de ocupação } \\
(\%)\end{array}$ & $\begin{array}{c}\text { № de } \\
\text { ocupaçõos } \\
\text { com } \\
\text { frequência }\end{array}$ & Pontuação \\
\hline 13 & 15 & 16 & $\begin{array}{l}\text { Miner. Central } \\
\text { Leste }\end{array}$ & $\begin{array}{l}\text { Vila do } \\
\text { Príncipe }\end{array}$ & Pessanha & 01789 & 23,3 & 031 & 04 \\
\hline 11 & 14 & 03 & $\begin{array}{l}\text { Inter. Pitan- } \\
\text { gui-Taman. }\end{array}$ & $\begin{array}{c}\text { S. José Del } \\
\text { Rei }\end{array}$ & Passatempo & 01483 & 25,4 & 032 & 04 \\
\hline 18 & 05 & 06 & Sudoeste & Jacuí & $\begin{array}{c}\text { São Se- } \\
\text { bastião da } \\
\text { Ventania }\end{array}$ & 01767 & 17,0 & 025 & 04 \\
\hline 07 & 12 & 16 & $\begin{array}{c}\text { Médio Baixo } \\
\text { R. Velhas }\end{array}$ & Sabará & $\begin{array}{c}\text { Morro da } \\
\text { Garça }\end{array}$ & 01283 & 23,8 & 023 & 04 \\
\hline 11 & 14 & 13 & $\begin{array}{l}\text { Inter. Pitan- } \\
\text { gui-Taman. }\end{array}$ & $\begin{array}{c}\text { S. José Del } \\
\text { Rei }\end{array}$ & $\begin{array}{l}\text { Carmo do } \\
\text { Japão }\end{array}$ & 01879 & 1,5 & 017 & 04 \\
\hline 11 & 14 & 19 & $\begin{array}{l}\text { Inter. Pitan- } \\
\text { gui-Taman. }\end{array}$ & $\begin{array}{c}\text { S. José Del } \\
\text { Rei }\end{array}$ & Oliveira & 02743 & 10,1 & 025 & 04 \\
\hline 14 & 03 & 14 & $\begin{array}{l}\text { Miner. Central } \\
\text { Oeste }\end{array}$ & Caeté & $\begin{array}{l}\text { Morro Ver- } \\
\text { melho }\end{array}$ & 00852 & 12,1 & 025 & 04 \\
\hline 14 & 11 & 12 & $\begin{array}{l}\text { Miner. Central } \\
\text { Oeste }\end{array}$ & Queluz & Suassuí & 01737 & 16,0 & 038 & 04 \\
\hline 14 & 12 & 10 & $\begin{array}{l}\text { Miner. Central } \\
\text { Oeste }\end{array}$ & Sabará & Mateus Leme & 03121 & 22,5 & 050 & 04 \\
\hline 18 & 05 & 01 & Sudoeste & Jacuí & Cabo Verde & 04585 & 18,1 & 026 & 04 \\
\hline 14 & 03 & 03 & $\begin{array}{l}\text { Miner. Central } \\
\text { Oeste }\end{array}$ & Caeté & Itambé & 02262 & 20,6 & 034 & 04 \\
\hline 14 & 06 & 04 & $\begin{array}{l}\text { Miner. Central } \\
\text { Oeste }\end{array}$ & Mariana & Pinheiro & 01113 & 11,7 & 022 & 04 \\
\hline 14 & 06 & 24 & $\begin{array}{l}\text { Miner. Central } \\
\text { Oeste }\end{array}$ & Mariana & $\begin{array}{l}\text { Mestre de } \\
\text { Campos }\end{array}$ & 00536 & 23,1 & 021 & 04 \\
\hline 14 & 06 & 03 & $\begin{array}{l}\text { Miner. Central } \\
\text { Oeste }\end{array}$ & Mariana & $\begin{array}{l}\text { Desterro do } \\
\text { Melo }\end{array}$ & 00757 & 23,0 & 021 & 04 \\
\hline 14 & 06 & 30 & $\begin{array}{l}\text { Miner. Central } \\
\text { Oeste }\end{array}$ & Mariana & São Gonçalo & 00948 & 21,8 & 022 & 04 \\
\hline 14 & 06 & 33 & $\begin{array}{l}\text { Miner. Central } \\
\text { Oeste }\end{array}$ & Mariana & Sumidouro & 00507 & 30,2 & 018 & 04 \\
\hline 14 & 11 & 11 & $\begin{array}{l}\text { Miner. Central } \\
\text { Oeste }\end{array}$ & Queluz & $\begin{array}{c}\text { São Caetano } \\
\text { das Paraope- } \\
\text { bas }\end{array}$ & 01053 & 24,4 & 018 & 04 \\
\hline 14 & 15 & 03 & $\begin{array}{l}\text { Miner. Central } \\
\text { Oeste }\end{array}$ & $\begin{array}{l}\text { Vila do } \\
\text { Príncipe }\end{array}$ & Rio do Peixe & 02277 & 30,2 & 030 & 04 \\
\hline 14 & 15 & 12 & $\begin{array}{l}\text { Miner. Central } \\
\text { Oeste }\end{array}$ & $\begin{array}{l}\text { Vila do } \\
\text { Príncipe }\end{array}$ & $\begin{array}{l}\text { Sto. Antônio } \\
\text { Abaixo }\end{array}$ & 01850 & 20,2 & 028 & 04 \\
\hline 17 & 04 & 11 & Sul Central & Campanha & $\begin{array}{l}\text { Bom Jesus } \\
\text { das Antas }\end{array}$ & 01605 & 19,7 & 010 & 04 \\
\hline 17 & 04 & 14 & Sul Central & Campanha & $\begin{array}{c}\text { Nossa } \\
\text { Senhora da } \\
\text { Soledade }\end{array}$ & 01438 & 16,1 & 020 & 04 \\
\hline 18 & 05 & 04 & Sudoeste & Jacuí & $\begin{array}{l}\text { São Carlos } \\
\text { do Jacuí }\end{array}$ & 03305 & 22,0 & 026 & 04 \\
\hline 15 & 02 & 06 & Mata & Barbacena & $\begin{array}{l}\text { Santo Antônio } \\
\text { de Juiz de } \\
\text { Fora }\end{array}$ & 01422 & 11,8 & 027 & 03 \\
\hline 11 & 14 & 04 & $\begin{array}{l}\text { Inter. Pitan- } \\
\text { gui-Taman. }\end{array}$ & $\begin{array}{c}\text { S. José Del } \\
\text { Rei }\end{array}$ & $\begin{array}{l}\text { Santana do } \\
\text { Jacaré }\end{array}$ & 00615 & 17,4 & 017 & 03 \\
\hline 16 & 01 & 02 & Sudeste & Baependi & Aiuruoca & 01664 & 15,6 & 025 & 03 \\
\hline 14 & 06 & 17 & $\begin{array}{l}\text { Miner. Central } \\
\text { Oeste }\end{array}$ & Mariana & Tapera & 01267 & 11,3 & 023 & 03 \\
\hline
\end{tabular}




\begin{tabular}{|c|c|c|c|c|c|c|c|c|c|}
\hline $\begin{array}{l}\text { Código } \\
\text { Região }\end{array}$ & $\begin{array}{l}\text { Código } \\
\text { Município }\end{array}$ & $\begin{array}{l}\text { Código } \\
\text { Distrito }\end{array}$ & Região & Município & Distrito & População & $\begin{array}{c}\text { População } \\
\text { com } \\
\text { informação } \\
\text { de ocupação } \\
(\%)\end{array}$ & $\begin{array}{c}\text { № de } \\
\text { ocupações } \\
\text { com } \\
\text { frequência }\end{array}$ & Pontuação \\
\hline 14 & 08 & 07 & $\begin{array}{l}\text { Miner. Central } \\
\text { Oeste }\end{array}$ & Ouro Preto & Casa Branca & 00686 & 27,6 & 017 & 03 \\
\hline 14 & 12 & 12 & $\begin{array}{l}\text { Miner. Central } \\
\text { Oeste }\end{array}$ & Sabará & $\begin{array}{l}\text { Sto. Antônio } \\
\text { do Rio Acima }\end{array}$ & 00540 & 28,9 & 023 & 03 \\
\hline 03 & 15 & 01 & Sertão & $\begin{array}{l}\text { Vila do } \\
\text { Príncipe }\end{array}$ & Bonfim & 02707 & 22,0 & 042 & 02 \\
\hline 13 & 03 & 05 & $\begin{array}{l}\text { Miner. Central } \\
\text { Leste }\end{array}$ & Caeté & $\begin{array}{l}\text { Santa Ana } \\
\text { dos Ferros }\end{array}$ & 02291 & 14,9 & 037 & 02 \\
\hline 16 & 13 & 02 & Sudeste & $\begin{array}{l}\text { S. João Del } \\
\text { Rei }\end{array}$ & Espírito Santo & 00524 & 9,5 & 015 & 02 \\
\hline 10 & 09 & 09 & Araxá & Paracatu & $\begin{array}{l}\text { Santíssimo } \\
\text { Sacramento }\end{array}$ & 01762 & 15,6 & 029 & 02 \\
\hline 16 & 01 & 03 & Sudeste & Baependi & Espírito Santo & 02295 & 13,4 & 020 & 02 \\
\hline 13 & 03 & 07 & $\begin{array}{l}\text { Miner. Central } \\
\text { Leste }\end{array}$ & Caeté & $\begin{array}{l}\text { São Domin- } \\
\text { gos do Prata }\end{array}$ & 02160 & 16,9 & 023 & 02 \\
\hline 15 & 02 & 07 & Mata & Barbacena & $\begin{array}{l}\text { São Fran- } \\
\text { cisco de } \\
\text { Paula }\end{array}$ & 01926 & 13,1 & 025 & 02 \\
\hline 09 & 09 & 13 & Triângulo & Paracatu & $\begin{array}{l}\text { São José do } \\
\text { Tijuco }\end{array}$ & 01625 & 13,5 & 029 & 02 \\
\hline 15 & 02 & 09 & Mata & Barbacena & $\begin{array}{l}\text { São Miguel e } \\
\text { Alma de João } \\
\text { Gomes }\end{array}$ & 00965 & 15,2 & 023 & 02 \\
\hline 16 & 01 & 08 & Sudeste & Baependi & Serrano & 02251 & 14,8 & 027 & 02 \\
\hline 18 & 05 & 08 & Sudoeste & Jacuí & $\begin{array}{l}\text { Senhor dos } \\
\text { Passos }\end{array}$ & 01792 & 18,8 & 021 & 02 \\
\hline 13 & 06 & 06 & $\begin{array}{l}\text { Miner. Central } \\
\text { Leste }\end{array}$ & Mariana & $\begin{array}{l}\text { Santa Rita do } \\
\text { Turvo }\end{array}$ & 01831 & 17,1 & 018 & 02 \\
\hline 15 & 02 & 03 & Mata & Barbacena & $\begin{array}{c}\text { Borda do } \\
\text { Campo e } \\
\text { Torres }\end{array}$ & 00774 & 7,1 & 015 & 02 \\
\hline 16 & 01 & 01 & Sudeste & Baependi & Alagoas & 01426 & 19,8 & 021 & 02 \\
\hline 16 & 13 & 10 & Sudeste & $\begin{array}{l}\text { S. João Del } \\
\text { Rei }\end{array}$ & Onça & 00899 & 16,9 & 020 & 02 \\
\hline 13 & 06 & 09 & $\begin{array}{l}\text { Miner. Central } \\
\text { Leste }\end{array}$ & Mariana & $\begin{array}{c}\text { São José do } \\
\text { Barroso }\end{array}$ & 01756 & 14,6 & 025 & 02 \\
\hline 15 & 06 & 10 & Mata & Mariana & $\begin{array}{l}\text { São José do } \\
\text { Paraopeba }\end{array}$ & 01138 & 13,3 & 022 & 02 \\
\hline 13 & 15 & 05 & $\begin{array}{l}\text { Miner. Central } \\
\text { Leste }\end{array}$ & $\begin{array}{l}\text { Vila do } \\
\text { Príncipe }\end{array}$ & Correntes & 02128 & 12,6 & 021 & 02 \\
\hline 14 & 06 & 26 & $\begin{array}{l}\text { Miner. Central } \\
\text { Oeste }\end{array}$ & Mariana & $\begin{array}{l}\text { N. Sra. de } \\
\text { Oliveira }\end{array}$ & 00839 & 12,5 & 014 & 02 \\
\hline 14 & 11 & 06 & $\begin{array}{l}\text { Miner. Central } \\
\text { Oeste }\end{array}$ & Queluz & $\begin{array}{l}\text { Dores da } \\
\text { Conquista }\end{array}$ & 01375 & 18,1 & 027 & 02 \\
\hline 14 & 12 & 25 & $\begin{array}{l}\text { Miner. Central } \\
\text { Oeste }\end{array}$ & Sabará & $\begin{array}{l}\text { Brumado do } \\
\text { Paraopeba }\end{array}$ & 01031 & 17,3 & 020 & 02 \\
\hline 15 & 06 & 29 & Mata & Mariana & $\begin{array}{l}\text { Dores do } \\
\text { Pomba }\end{array}$ & 00782 & 17,1 & 015 & 02 \\
\hline 17 & 04 & 10 & Sul Central & Campanha & $\begin{array}{c}\text { S. Sebas. e } \\
\text { São Roque } \\
\text { do Bom } \\
\text { Retiro }\end{array}$ & 00574 & 14,8 & 006 & 02 \\
\hline 11 & 14 & 07 & $\begin{array}{l}\text { Inter. Pitan- } \\
\text { gui-Taman. }\end{array}$ & $\begin{array}{c}\text { S. José Del } \\
\text { Rei }\end{array}$ & Cláudio & 02777 & 12,2 & 029 & 01 \\
\hline
\end{tabular}




\begin{tabular}{|c|c|c|c|c|c|c|c|c|c|}
\hline $\begin{array}{l}\text { Código } \\
\text { Regiẫo }\end{array}$ & $\begin{array}{l}\text { Código } \\
\text { Município }\end{array}$ & $\begin{array}{l}\text { Código } \\
\text { Distrito }\end{array}$ & Região & Município & Distrito & População & $\begin{array}{c}\text { População } \\
\text { com } \\
\text { informação } \\
\text { de ocupação } \\
(\%)\end{array}$ & $\begin{array}{l}\text { № de } \\
\text { ocupações } \\
\text { com } \\
\text { frequência }\end{array}$ & Pontuação \\
\hline 16 & 13 & 07 & Sudeste & $\begin{array}{l}\text { S. João Del } \\
\text { Rei }\end{array}$ & $\begin{array}{l}\text { Piedade do } \\
\text { Rio Grande }\end{array}$ & 01290 & 15,3 & 019 & 00 \\
\hline 07 & 12 & 19 & $\begin{array}{c}\text { Médio Baixo } \\
\text { R. Velhas }\end{array}$ & Sabará & Livramento & 01360 & 14,0 & 028 & 00 \\
\hline 04 & 07 & 02 & Minas Novas & $\begin{array}{l}\text { Minas } \\
\text { Novas }\end{array}$ & Salinas & 03099 & 12,8 & 018 & 00 \\
\hline 05 & 09 & 10 & Paracatu & Paracatu & Morrinhos & 01195 & 8,3 & 012 & 00 \\
\hline 14 & 06 & 07 & $\begin{array}{l}\text { Miner. Central } \\
\text { Oeste }\end{array}$ & Mariana & $\begin{array}{l}\text { Santo Antônio } \\
\text { do Bacalhau }\end{array}$ & 00440 & 14,1 & 011 & 00 \\
\hline 14 & 06 & 37 & $\begin{array}{l}\text { Miner. Central } \\
\text { Oeste }\end{array}$ & Mariana & Braz Pires & 00842 & 2,1 & 007 & 00 \\
\hline 16 & 13 & 01 & Sudeste & $\begin{array}{c}\text { S. João Del } \\
\text { Rei }\end{array}$ & Carrancas & 01714 & 7,2 & 018 & 00 \\
\hline
\end{tabular}




\section{Resumen}

Un estudio de la calidad de la información censitaria en listas nominativas y una aproximación a la estructura ocupacional de la provincia de Minas Gerais

Este artículo tiene como objetivo evidenciar la necesidad de una evaluación de la calidad de la información censitaria en listas nominativas de habitantes del siglo XIX, proponer la clasificación, según la calidad de la información, para las unidades espaciales de información del Censo de 1831-32, realizado en la provincia de Minas Gerais y presentar resultados preliminares y generales de la estructura ocupacional de Minas, en función al referido Censo, que contemplan la diversidad regional de la provincia. La demostración del efecto de la calidad de la información de ocupación sobre la estructura ocupacional, en tres niveles (provincial, regional y por distrito), demostró que el trabajo con censos históricos no puede prescindir de la evaluación del alcance y de los límites de los datos.

Palabras-clave: Calidad de la información censitaria. Estructura ocupacional. Minas Gerais. Siglo XIX.

\section{Abstract}

A study of the quality of the census information on lists of names and an approximation to the occupational structure of the Province of Minas Gerais, Brazil

This article has the objective of showing the need for evaluating the quality of census information in named lists of inhabitants in the 19th century. The aim is also to propose a classification, according to the quality of the information, for the spatial units of information of the 1831-32 Census carried out in the Province (now State) of Minas Gerais, Brazil and present preliminary and general findings on the occupational structure of the province on the basis of the mentioned census, as these results take into account the regional diversity of the province at the time. The demonstration of the effect of the quality of the information of occupation on the occupational structure on three levels of aggregation (provincial, regional and district) showed that researchers should not fail to assess the extent and limits of the data available when dealing with historical censuses.

Keywords: Quality of census information. Occupational structure. Minas Gerais. 19th century.

Recebido para publicação em 01/06/2009 Aceito para publicação em 11/02/2010 